\title{
Increasing longevity and life satisfaction: is there a catch to living longer?
}

\author{
Janina Nemitz ${ }^{1,2,3}$ (D)
}

Received: 16 December 2019 / Accepted: 16 February 2021 / Published online: 3 May 2021

(C) The Author(s) 2021

\begin{abstract}
Human longevity is rising rapidly all over the world, but are longer lives more satisfied lives? This study suggests that the answer might be no. Despite a substantial increase in months of satisfying life, people's overall life satisfaction declined between 1985 and 2011 in West Germany due to substantial losses of life satisfaction in old age. When compared to 1985, in 2011, elderly West Germans were, on average, much less satisfied throughout their last five years of life. Moreover, they spent a larger proportion of their remaining lifetime in states of dissatisfaction, on average. Two important mechanisms that contributed to this satisfaction decline were health and social isolation. Using a broad variety of sensitivity tests, I show that these results are robust to a large set of alternative explanations.
\end{abstract}

Keywords Life satisfaction · Happiness · Longevity · Terminal satisfaction · Happy life expectancy · Sullivan's method

JEL Classification I10 $\cdot \mathrm{I} 31 \cdot \mathrm{J} 11$

\section{Introduction}

Over the last four decades, human life expectancy has, on average, increased by one year every four years in OECD countries (OECD 2016). The rise in life expectancy

\footnotetext{
Responsible editor: Alessandro Cigno

Janina Nemitz

janina.nemitz@helsana.ch

1 Department of Economics, University of Zurich, Zurich, Switzerland

2 School of Management and Law, ZHAW Zurich University of Applied Sciences, Winterthur, Switzerland

3 Present address: Helsana Group, Helsana Supplementary Insurances Ltd, Zurich, Switzerland
} 
holds true for both men and women, at various ages, and across countries, although recently life expectancy has plateaued, if not fallen, in the UK and the USA (e.g., Case and Deaton 2015; Chetty et al. 2016; Marmot et al. 2020). But are longer lives more satisfied lives? This question is vital for individuals and public policymakers because longer lives might come at the price of lower quality and life satisfaction in old age. Longer lives will be less valuable to people if the additional life years are spent in dissatisfaction and this causes overall life satisfaction (i.e., life satisfaction totaled over the life course minus a death value) to decrease. Both issues are pivotal in the context of private and public decision-making, where decision makers may face the tradeoff between lengthening human life and enhancing the quality of life.

Despite its importance for public policy and individuals, little is known about how life satisfaction in old age has changed with improved longevity over time. The previous literature has almost exclusively focused on health-related measures (e.g., Crimmins and Beltrán-Sánchez 2011; Jagger and Robine 2011; and Chatterji et al. 2015 for recent reviews), although health is only one determinant of life satisfaction (Easterlin 2002, 2003) and people partially adapt to poor states of health (Oswald and Powdthavee 2008; McNamee and Mendolia 2014). Evidence on life satisfaction and related concepts of well-being is limited to studies that investigate time trends of average and cumulative life satisfaction (e.g., Perenboom et al. 2004; Yang 2008; Realo and Dobewall 2011), or that analyze patterns of life satisfaction across a person's lifecycle (e.g., Blanchflower and Oswald 2004, 2008; Baird et al. 2010). However, these studies fail to control for time to death (Gerstorf et al. 2010) and reveal little about changes in terminal life satisfaction over time. Moreover, due to their reliance on cross-sectional data, studies are often unable to separate age, cohort, and period effects (Schilling 2005).

In this study, I combine two approaches to investigate how life satisfaction in old age has changed with improved longevity in West Germany between 1985 and 2011. The time-to-death approach estimates time trends of average life satisfaction by time to death. This approach focuses on the last five years of life because, unlike earlier life years in old age, these years are characterized by a sharp satisfaction decline (Gerstorf et al. 2008a, b, 2010). Due to its distinction by time to death, this approach can uncover varying end-of-life satisfaction patterns in aging societies across time, such as a shift in the onset or a change in the slope of terminal decline. Hence, this approach is particularly useful for informing end-of-life decision-making in modern societies. The life-expectancy approach estimates time trends of satisfied life expectancy at age 60. Satisfied life expectancy at age 60 is a summary measure that collapses age-specific mortality and satisfaction prevalence rates observed in a given year into a single number. It provides information on the number of satisfied life years that a member of a 60 -year-old life table cohort can expect to live given agespecific mortality and satisfaction prevalence rates as of that year. This approach adds to the time-to-death approach by accumulating satisfied life years beyond the age of 60 (analysis in absolute terms) and relating them to total remaining lifetime (analysis 
in relative terms) for the average individual. In doing so, it weighs increases in (satisfied) lifetime against possible satisfaction losses at the end of life and, thus, informs policymakers about the overall value of longer lives. ${ }^{1}$

To overcome the major shortcomings of previous studies, I use data from the longest running household panel with continuous information on overall life satisfaction, the German Socio-Economic Panel (GSOEP). This data set is unique in that it allows researchers to closely follow a respondent's life satisfaction over the life course until death for more than 30 years now. Due to its longitudinal structure and a large set of controls, this data set allows me to rule out many alternative explanations for the observed life satisfaction changes over time, including, for example, compositional, cohort, period, and time-in-panel effects.

This study contributes to the existing literature in four important ways. First, it is the first study to analyze how life satisfaction in the final period of life has changed with improved longevity over time. It provides evidence that the terminal decline in life satisfaction holds over time but has increased in length and magnitude of decline, thereby adding to the small but growing literature on end-of-life satisfaction (e.g., Gerstorf et al. 2008a, b, 2010; Palgi et al. 2010; Berg et al. 2011). Second, this study challenges the conclusions that were drawn about life satisfaction in aging societies based on the age-satisfaction curve (e.g., Steptoe et al. 2015). By introducing a novel framework, this study highlights the importance of the final period of life, as opposed to age, when drawing conclusions about satisfaction patterns in aging societies across time. Third, contrary to most related studies that exploit variation in longevity over time to study well-being in aging societies (e.g., Perenboom et al. 2004; Yang 2008), this study carefully explores the role of explanations other than improved longevity. Therefore, it can exclude a large set of alternative explanations for the satisfaction decline in West Germany over time. Fourth, this study furthers our understanding of successful aging by shedding light on two important mechanisms: health and social isolation. Although these mechanisms are not new to the literature (see Oswald and Powdthavee 2008 for the former and Helliwell 2003, 2006 for the latter), this study is the first to show that health and social isolation also play an important role in aging societies over time.

This paper proceeds as follows. Section 2 provides some background information and gives an overview of related studies. Section 3 discusses the framework that motivates the two empirical approaches of this paper. Section 4 describes the data. Section 5 presents the time-to-death approach and its results. Section 6 presents the life-expectancy approach and its results. Section 7 discusses two potential mechanisms (health and social isolation) and provides some evidence for these mechanisms. Section 8 concludes and provides some policy implications.

\footnotetext{
${ }^{1}$ In what follows, the term final period of life refers to the last five years of life (time-to-death approach) or the period of terminal satisfaction decline, which may comprise more or less than five years, depending of the country and the reference year. The term remaining period of life refers to all life years after age 60 (life-expectancy approach).
} 


\section{Background}

Life satisfaction is an important contributor to the general construct of subjective well-being. It indicates the extent to which people positively evaluate the overall quality of their life as-a-whole (Veenhoven 1996b). That is, in contrast to hedonic (e.g., feelings of happiness, sadness, stress) or eudemonic measures of well-being (e.g., sense of meaning and purpose in life), it provides a global assessment of the people's quality and goodness of life (Steptoe et al. 2015). Life satisfaction is commonly assessed by single direct questions in surveys, with assessment scales ranging from very satisfying to very dissatisfying. ${ }^{2}$

Empirical research on life satisfaction has grown exponentially since its start in the 1970s (Veenhoven 2015). This growth is likely explained by three matters: First, single-item direct questions on life satisfaction were integrated in many national and international surveys (see Dolan et al. 2008 for an overview). Second, previous research in psychology, sociology, and economics has shown that life satisfaction correlates well with a large set of outcomes and major life events (e.g., Di Tella et al. 2001; Frijters et al. 2004b; Deaton 2008; Clark et al. 2008), and predicts relevant future behavior (e.g., Koivumaa-Honkanen et al. 2001 for suicide). Overall, the reliability, validity, and sensitivity of life satisfaction measures is fairly high. ${ }^{3}$ Third, life satisfaction is coming to the forefront of the public policy discourse, in which the improvement of population satisfaction is emerging as a key societal aspiration (Steptoe et al. 2015). ${ }^{4}$

Facing the challenges of population aging, an important field of research on life satisfaction has investigated the association between age and satisfaction (see Steptoe et al. 2015 for an excellent review). Using data from large-scale national and international surveys, studies in this field often, but not always, find that the association between age and life satisfaction is U-shaped with a strong dip in life satisfaction in middle age, and possibly another downturn in old age (e.g., Blanchflower and Oswald 2004, 2008, 2019; Wunder et al. 2013; Graham and Ruiz Pozuelo 2017; Blanchflower 2021). However, the downturn in old age almost vanishes upon controlling for time to death (e.g., Gerstorf et al. 2008a, 2010). This suggests that life satisfaction in old age is a function of time to death rather than age. Nevertheless, patterns of terminal life satisfaction decline may depend on age. Exploring interindividual differences in terminal satisfaction decline, Gerstorf et al. (2008b), for example, show that individuals dying at older ages spend more time in the period of terminal satisfaction decline than individuals dying at earlier ages. However, it is yet unknown how such crosssectional results translate to changes in overall life satisfaction in aging societies over time.

\footnotetext{
${ }^{2}$ However, multi-item measures such as the satisfaction with life scale also exist (Diener et al. 1985).

${ }^{3}$ There is, however, an ongoing debate about whether or not multi-item measures outperform single-item measures in terms of such outcomes (Veenhoven 1996a; Diener et al. 2013).

${ }^{4}$ The recent issue "On Happiness Being the Goal of Government" from Behavioural Public Policy provides an excellent overview on whether happiness research using, e.g., subjective well-being measures should inform public policy. In Frijters et al. (2020), the authors provide a strong argument for the use of life satisfaction as the goal of government, but also discuss current barriers to its adoption.
} 
A second strand of research has analyzed changes in life expectancy in wellbeing within a country across time. Most studies in this field estimate healthy life expectancy and-depending on the health indicator and country of investigationreport mixed results (see Jagger and Robine 2011 for a review). Only two studies use concepts of well-being that are more closely related to satisfaction. Perenboom et al. (2004) estimate life expectancy in hedonic well-being at the ages 16 and 65 and show that it significantly increased for men and women between 1989 and 1998 in the Netherlands. Yang (2008) computes happy life expectancy for both men and women at various ages in the United States. He finds that happy life expectancy at all ages rose in both absolute (number of years) and relative terms (proportion of life) between 1970 and 2000. Thus, both studies suggest that increases in longevity came with improvements in well-being. However, it is yet unknown whether these results also generalize to other countries and later time periods.

In what follows, I present a simple framework that furthers our understanding of the age-satisfaction association within the context of an aging society.

\section{A framework}

To evaluate the impact of improved longevity, it is necessary to compare the overall quality of two representative lives that differ with respect to their length. In economics, the quality of life is measured by lifetime utility. Lifetime utility captures the idea that people attach value to both length and quality of life, thus accounting for the fact that the value of a longer life strongly depends on its quality. As life satisfaction is a good proxy for utility (Benjamin et al. 2012, 2014; Fleurbaey and Schwandt 2015), a measure of overall life satisfaction is obtained by replacing contemporaneous utility scores in the lifetime utility function with their corresponding reported life satisfaction scores. Assuming that people attach equal weight to each year of life (i.e., there is no discounting), overall life satisfaction of the representative agent is then given by

$$
T L S=\sum_{a=0}^{A}\left(L S_{a}-L S_{d}\right),
$$

where $A \in \mathbb{R}_{+}$is the age in the last year of life, $L S_{a} \in[\underline{L S}, \overline{L S}]$ is the life satisfaction score at age $a$, and $L S_{d} \in[\underline{L S}, \overline{L S}]$ is the life satisfaction score that is attached to death. The normalization by $L S_{d}$ accounts for the fact that there are states of life that are considered not worth living (e.g., Ditto et al. 1996; Rubin et al. 2016). In this framework, an increase in longevity from $A$ to $A^{\prime}$ is considered to be welfare improving if $T L S^{\prime}>T L S$, i.e., if overall life satisfaction of the representative agent increases.

One major drawback of this framework is its reliance on the cardinality assumption. This is because life satisfaction in surveys is typically measured on an ordinal scale. To remain as close as possible to the notion of overall life satisfaction without having to rely on cardinality, I use a combination of two approaches: the time-todeath approach and the life-expectancy approach. The former, new to the satisfaction literature, rests on a minimum set of assumptions and can be sufficient to conclude 
that past increases in lifetime were welfare improving. The life-expectancy approach complements it for the cases where increases in (satisfied) lifetime have to be weighed against losses in end-of-life satisfaction. This latter approach requires some additional assumptions, most importantly, the choice of a cutoff value to distinguish between states of satisfaction and dissatisfaction. ${ }^{5}$

In the following, the underlying idea of the approaches will be presented. For the time-to-death approach, it is useful to observe two important facts about the evolution of life satisfaction in old age:

1. Stability-despite-loss paradox: For years more distant from death, life satisfaction is relatively stable in old age despite aging-related losses (Diener et al. 1999; Kunzmann et al. 2000; Schilling 2006).

2. Terminal decline: For years close to death, life satisfaction strongly declines with proximity to death. This decline is linear, possibly with a more pronounced drop in the last year of life, and it starts, on average, roughly three to five years before death (e.g., Gerstorf et al. 2008a, b, 2010; Palgi et al. 2010; Berg et al. 2011).

This suggests that it is crucial to investigate changes in terminal life satisfaction over time to understand whether overall life satisfaction has increased with improved longevity in aging societies.

Characteristics of the terminal life satisfaction decline might change with improved longevity. It is, for example, possible that the terminal decline extends, leading to much lower life satisfaction scores immediately before death. Alternatively, there might be a shift in the onset of terminal decline to an older age, or a change in the slope of terminal decline. Figure 1 illustrates some of these possible changes for the representative agent (graphs on the left). How these changing terminal life satisfaction patterns over time can be uncovered by analyzing time trends of average life satisfaction by time to death is illustrated in Fig. 1 on the right. ${ }^{6}$ If, for example, a downward sloping time trend of average life satisfaction for the last year of life is observed, this is consistent with an extension of the terminal decline (see panels a and d). A change in the slope of terminal decline over time is reflected by narrowing (see panel c) or widening (see panel d) gaps between the average life satisfaction trends over time.

A clear indication for a welfare improvement in terms of overall life satisfaction is the pattern of average life satisfaction trends that are upward sloping or flat over time. This is easily seen for the limiting case, which is depicted in panel b of Fig. 1. If the shift in the onset of terminal decline exactly corresponds to the shift in the age at

\footnotetext{
${ }^{5}$ The life satisfaction scale of the GSOEP, for instance, does not specify where "dissatisfied" stops and "satisfied" starts.

${ }^{6}$ As usual, I compute averages to get from individuals to the representative agent of a society. Interestingly, time trends of the proportion of elderly people in each state of satisfaction would lead to the same conclusion as average life satisfaction trends. This implies that, despite averaging, the results do not rest on the cardinality assumption.
} 

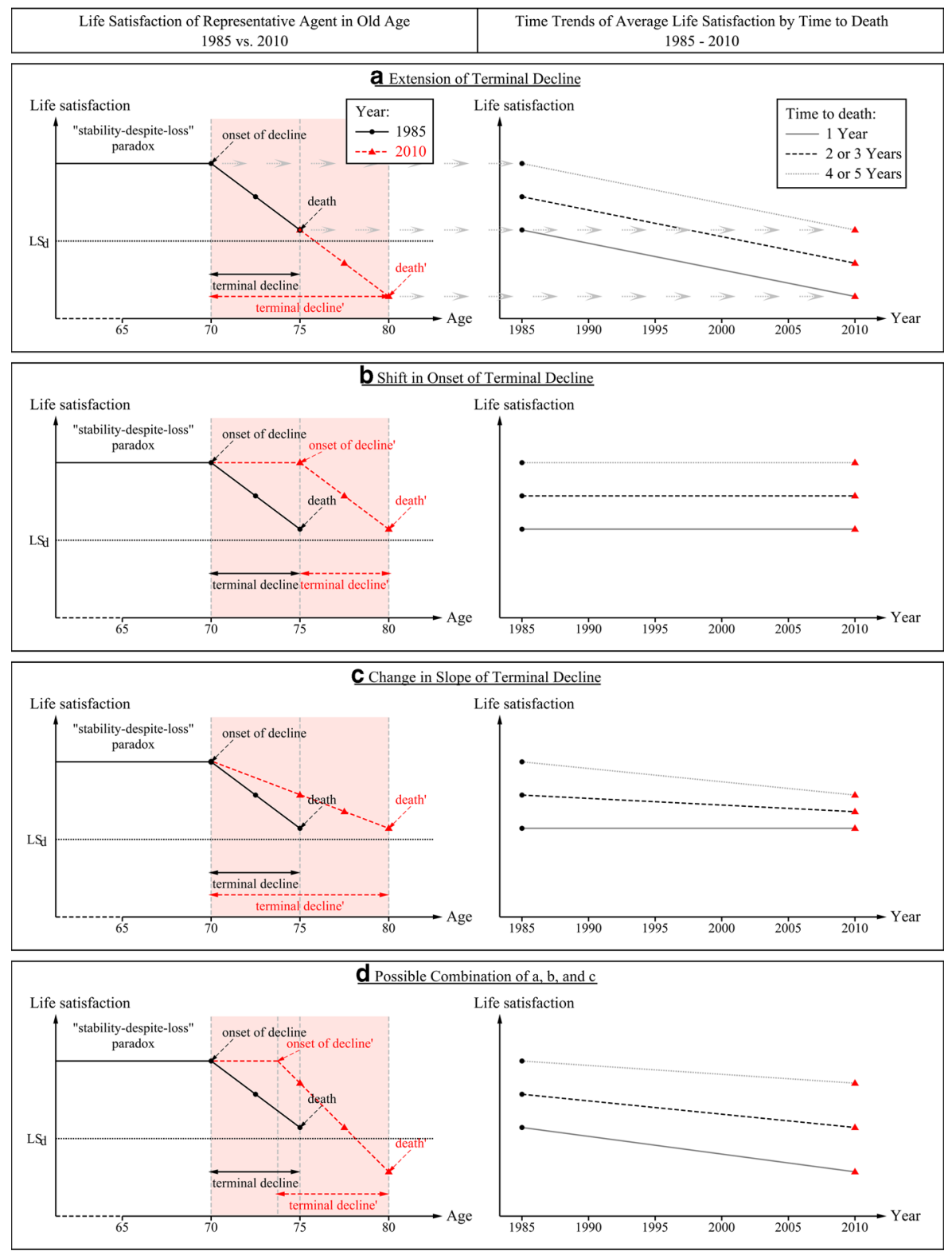

Fig. 1 Illustration of the time-to-death approach. This figure illustrates how possible changes of terminal life satisfaction patterns for the representative agent over time (graphs on the left) can be uncovered by focusing on the last five years of life and analyzing time trends of average life satisfaction by time to death (graphs on the right). Each panel (a to d) shows a different change in terminal life satisfaction patterns. Source: Author's representation

death, the additional lifetime is exclusively spent in satisfaction. Further, considering that life satisfaction scores in the terminal decline phase are identical, it must be that 
overall life satisfaction of the representative agent increases. This holds even in the absence of the cardinality assumption. ${ }^{7}$ In contrast, if average life satisfaction trends are downward sloping, this is a necessary but not sufficient condition for a welfare loss in terms of overall life satisfaction. The reason is that downward sloping time trends indicate a deterioration of the final period of life that can be compensated by an increase in satisfied lifetime. That is, overall life satisfaction may increase or decrease, depending on how losses in terminal life satisfaction are valued relative to gains in satisfied lifetime. Hence, in this case a summary measure is required to obtain clear predictions.

As this summary measure, I use satisfied life expectancy at age 60. It does not rely on the cardinality assumption, but requires weighting increases in satisfied lifetime against increases in dissatisfied lifetime to allow for welfare comparisons across time. To do so, I compare the proportion of expected satisfied lifetime to expected total lifetime at the age of 60 across time. Under the assumption that at the age of 60 , people prefer a high proportion of satisfied lifetime over a higher number of satisfied life years, successful aging requires this proportion to be non-decreasing over time. This implies, however, that people are willing to accept an extension of the dissatisfied lifetime at the end of their life, provided that it is not too long compared to the extension in satisfied lifetime. This is one important feature that also finds empirical support in discrete choice experiments on the willingness-to-pay for life extensions (Pennington et al. 2015; Ahlert et al. 2016; Fischer et al. 2018).

Overall, this section argues that we need to observe an increase in the proportion of satisfied lifetime at the age of 60 to conclude that overall life satisfaction has increased with improved longevity. This is clearly the case if average life satisfaction trends by time to death are upward sloping or flat. However, it may also be the case if we observe a deterioration of the final period of life (downward sloping trends) because a possible increase in satisfying lifetime may compensate for a worse final period of life.

\section{Data}

This study uses data from the German Socio-Economic Panel. The GSOEP is a nationally representative longitudinal study of households in Germany. It was launched in 1984. Initially, it included West German households only. After the German reunification, a representative sample of East German households was added. Currently, more than 20000 adult residents are interviewed on an annual basis. The survey content includes rich information on demographics, household composition, health, attitudes, and values. ${ }^{8}$

\footnotetext{
${ }^{7}$ However, in the absence of the cardinality assumption, the magnitude of the welfare gain cannot be quantified. Under the cardinality assumption (and in continuous time), in panel B overall life satisfaction for 1985 or 2010 would correspond to the area between the respective age-satisfaction curve and the horizontal line at $L S_{d}$. The welfare gain would correspond to the difference between the two areas for 2010 and 1985, i.e., the area between the black and the red age-satisfaction curves, and the horizontal line at $L S_{d}$.

${ }^{8}$ For further information on content and sampling structure of the GSOEP, see Wagner et al. (2007).
} 
Information on overall life satisfaction has been gathered annually since 1984. It is collected using the question "How satisfied are you with your life currently, all things considered?" The answer is measured on an 11-point Likert scale, ranging from 0 (very dissatisfied) to 10 (very satisfied). Information on mortality and the year of death is obtained either directly at the yearly interviews from remaining household members, relatives, and neighbors, or indirectly from official registries, which were contacted throughout dropout studies. Time to death is calculated by subtracting the survey year from the year of death. Lacking information on the month of death, I refer to people as being one year, two or three years, and four or five years before death in what follows.

Beyond the GSOEP data, two additional data sources are used. I use data from the official German Death Statistics (GBE 2016) to adjust the estimates throughout the time-to-death approach. This adjustment was necessary because women are underrepresented among older GSOEP participants. Scale weights were constructed based on gender, five-year age-at-death intervals, German nationality, and time to death. They were merged to the GSOEP by year of death and group characteristics (i.e., gender, age, and German nationality), implicitly assuming that the composition of the population in West Germany was constant in the five years before death. To compute satisfied life expectancy at age 60, I use gender-specific period life tables for West Germany. They have been provided by the German Statistical Office on an annual basis since the late 1950s (German Federal Statistical Office 2012a, b).

The two main samples were obtained as follows: I used data from the GSOEP samples A to F. ${ }^{9}$ The elderly in East Germany were excluded because their life satisfaction levels were strongly affected by the institutional and ideological changes in East Germany following German reunification (e.g., Frijters et al. 2004a; Vogel et al. 2017). This renders their data less appropriate for longitudinal comparisons. Furthermore, I excluded migrants because the composition and the share of migrants changed over time. These changes are likely problematic because reported satisfaction levels vary with nationality (Steptoe et al. 2015). Finally, I restricted the analysis to the elderly, i.e., I focused on respondents who died at age 60 or older and were within five years of death (time-to-death sample) or respondents who were aged 60 plus at the time of the survey interview irrespective of their remaining lifetime (lifeexpectancy sample). The age threshold of 60 was chosen because in the last three decades the vast majority of age-related deaths in West Germany occurred at the age of 60 or older. ${ }^{10}$

Figure 2 shows the distribution of life satisfaction scores for the time-to-death and life-expectancy samples. It illustrates for both samples that the life satisfaction distribution is highly left-skewed. For the life-expectancy sample, almost $50 \%$ of the responses are concentrated on the categories seven and eight, and only $7.7 \%$ of the respondents report a life satisfaction score below five (the midpoint of the scale). The

\footnotetext{
${ }^{9}$ The samples A and B represent the original samples of West German households. The samples C to F were added at later stages to include East German households and to compensate for attrition.

${ }^{10}$ According to the official German Death Statistics (Gesundheitsberichterstattung des Bundes (GBE) 2016), in West Germany less than $8 \%$ of the people with German nationality died before age 60 in 1985. In 2010 , this share was even lower at $4.6 \%$.
} 

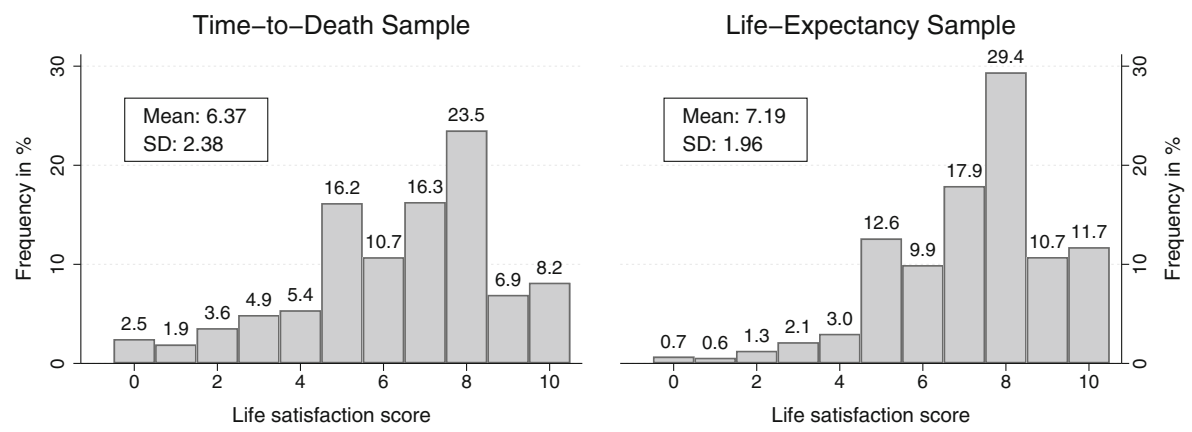

Fig. 2 Distribution of life satisfaction scores by sample. $N=9371$ (time-to-death sample) and $N=26870$ (life-expectancy sample). Life satisfaction is measured on an 11-point Likert scale, ranging from 0 (very dissatisfied) to 10 (very satisfied). Source: Author's calculations based on SOEPv30 (1984-2013)

distribution of the time-to-death sample is less skewed than the distribution of the lifeexpectancy sample. The stronger concentration of responses at lower life satisfaction scores for the time-to-death sample is consistent with the terminal decline in life satisfaction.

\section{Time-to-death approach}

This section analyzes how terminal life satisfaction changed with improved longevity across time. Before presenting the results, additional details on the estimation are provided.

\subsection{Empirical strategy}

Time trends of average life satisfaction were estimated based on 2446 West German respondents who were within five years of death between 1985 and 2011 (unbalanced sample). Satisfaction trends are shown separately by time to death to allow us to uncover changes in both slope and onset of terminal satisfaction decline. I estimated three-year moving averages in order to smooth the satisfaction trends slightly. Estimates in a given year rely on roughly 200 to 400 observations. Weighted estimates are reported throughout using the scale weights that were described in Section 4.

A meaningful interpretation of these estimates relies on the assumption that changes in terminal life satisfaction over time can only be attributed to increased longevity. This requires ruling out a large variety of time-varying factors that may also contribute to changes in terminal life satisfaction over time. Therefore, following the results, a broad set of sensitivity checks shows that the time-to-death results cannot be explained by compositional, cohort, or time-in-panel effects, general macroeconomic trends or aging-unrelated period effects, an endogenous onset of disease and terminal life satisfaction decline, an increasingly negatively selected sample due to the age restriction, or increasing attrition among the elderly across time. 


\subsection{Results}

Figure 3 depicts the time trends of average life satisfaction and average age at death for elderly West Germans without a migration background who were one year (solid line in dark gray), two or three years (dashed-dotted line in black), and four or five years (dashed line in light gray) prior to death. ${ }^{11}$ This figure clearly suggests that the last five years of life, on average, deteriorated with improved longevity over time. The graph on the left indicates that average life satisfaction prior to death strongly declined over time, irrespective of the time to death. Between 1985 and 2011, average life satisfaction decreased by almost one Likert point, which corresponds to about half a standard deviation of life satisfaction. ${ }^{12}$ The decline in life satisfaction reaches statistical significance, and it is large, when compared to the change in life satisfaction that is caused by a change in alternative respondents' characteristics such as education or employment status (e.g., Oreopoulos 2007 for education and Clark and Oswald 1994, Winkelmann and Winkelmann 1995, and Kassenboehmer and Haisken-DeNew 2009 for unemployment and job loss). The graph on the right demonstrates that the decline in life satisfaction went along with an increase in the average age at death. ${ }^{13}$ Time series correlation coefficients for the satisfaction and age at death trends range between -0.58 and -0.78 .

Linking the results in Fig. 3 to the stylized profiles in Fig. 1, Fig. 3 offers some additional insights. First of all, it shows that the terminal life satisfaction decline also holds in aging societies across time. In each given year, life satisfaction declines, on average, with proximity to death. However, patterns of the terminal satisfaction decline have changed with improved longevity over time. Until 2000 average satisfaction trends fell in parallel. This is consistent with an extension of the terminal decline and, thus, substantially lower life satisfaction scores in the last five years of life (cf. panel a in Fig. 1). After 2000, average life satisfaction continued to decrease for the elderly who were more than one year prior to death, but stayed relatively constant for those in the last year of life. This narrowing gap between the average life satisfaction trends is consistent with a flattening slope of terminal decline over time (cf. panel c in Fig. 1). Finally, as average life satisfaction four to five years prior to death did not stay constant but decreased over time, the possible shift in the onset of

\footnotetext{
${ }^{11}$ Each trend line stops at a different point in time as a GSOEP respondent's death is only observed until the mid of 2013. Respondents who died in 2013 were one year prior to death in 2012, three years prior to death in 2010, and five years prior to death in 2008. To avoid compositional changes in the study population across years when computing three-year averages, the corresponding trend lines end in 2011, 2009, and 2007.

${ }^{12}$ For more distant years before death trend lines stop earlier. Hence, the observed satisfaction decline is smaller. With 0.64 and 0.89 Likert points it corresponds to about one-third and two-fifths of a standard deviation.

${ }^{13}$ In a balanced panel (i.e., in the absence of attrition and sample refreshment), time trends of the average age at death should be identical in shape. They would simply be shifted to the right with increasing proximity to death because people who were, for example, four or five years prior to death in 1985 correspond to those who were two or three years prior to death in 1987. The fact that I find time trends of the average age at death that are parallel to each other (also pre-weighting) suggests for the GSOEP that attrition with respect to age is neither increasing nor decreasing in the final period of life over time, despite improved longevity.
} 

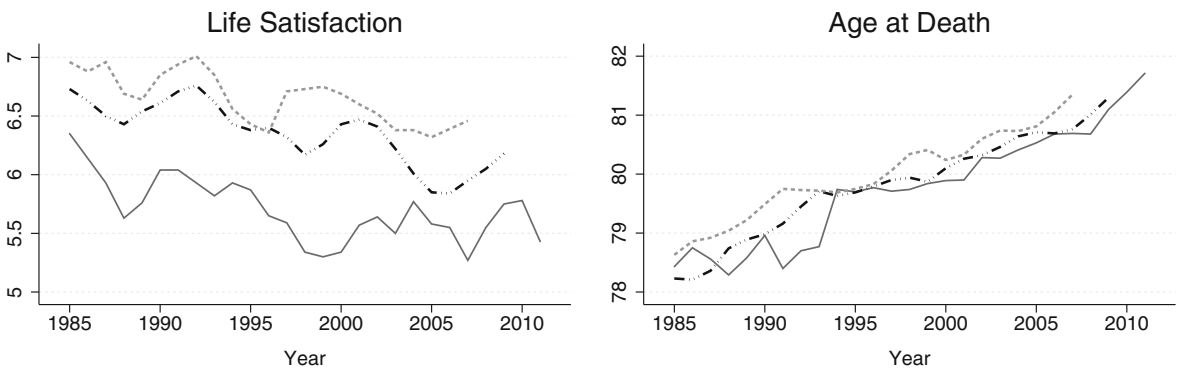

Time to death: — 1 Year $\quad \ldots \ldots . . . .2$ or 3 Years $\quad \ldots . . . . .4$ or 5 Years

Fig. 3 Average life satisfaction and average age at death for elderly West Germans within five years of death, 1985-2011, by time to death. Estimated based on the time-to-death sample. Estimates in a given year represent three-year averages. Life satisfaction is measured on an 11-point Likert scale, ranging from 0 (very dissatisfied) to 10 (very satisfied). Age at death is measured in years. Source: Author's calculations based on GBE (2016) and SOEPv30 (1984-2013)

terminal decline was smaller than the shift in the age at death (cf. limiting case in panel $b$ in Fig. 1). That is, the duration of the terminal decline phase extended. This extension came with satisfaction losses in old age that go beyond the last five years of life.

\subsection{Sensitivity tests}

This section discusses the results of a large battery of sensitivity checks. Supporting figures and tables are provided in Appendix 1.

To assess the role of compositional effects, cohort effects, and time-in-panel effects, I estimated weighted individual-level life satisfaction regressions by time to death. ${ }^{14}$ Using the pooled three-year average data set, I regressed life satisfaction on a set of year dummies, subsequently adding distinct sets of controls to the regressions: To account for compositional effects, I added a dummy for males, years of education, net household income, dummies for the interview month, and dummies for the state of residence; to account for cohort effects, I added five-year cohort dummies; and to account for time-in-panel effects, I added a linear term for time-in-panel duration. ${ }^{15}$

\footnotetext{
${ }^{14}$ Cohort effects may arise because of Germany's unique history during and after World War II. For example, because of their war experience earlier born cohorts may more positively assess their current life than later born cohorts when making intrapersonal comparisons, though empirical evidence in this regard is mixed (Baird et al. 2010; Gwozdz and Sousa-Poza 2010)). Time-in-panel effects can appear because reported life satisfaction is negatively related to the duration spent in a panel (e.g., Kassenboehmer and Haisken-DeNew 2012; Baetschmann 2014).

${ }^{15}$ The classical identification problem between age, year, and cohort does not arise because age is not included in these regressions. The coefficient on time-in-panel duration is identified due to sample refreshment and non-response. Household income is deflated and need-weighted, i.e., it adjusts for purchasing power, and household size using modified OECD equivalence weights.
} 
Figure 7 in Appendix 1 graphically depicts the year dummy coefficient estimates of these regressions relative to the year 1985. It demonstrates that the decline in terminal life satisfaction across time persists, even after controlling for compositional, cohort, and time-in-panel effects, although there is some evidence that time-in-panel effects contributed to the decline of end-of-life satisfaction over time. ${ }^{16}$

To investigate whether the decline in terminal life satisfaction over time is driven by macroeconomic effects (e.g., German reunification) or simply represents a general aging-unrelated time trend, I used a difference-in-difference type of approach. ${ }^{17}$ More specifically, I estimated time trends of average life satisfaction for three control groups of West German respondents that were formed based on age. In order to rule out the possibility that macroeconomic events or a general time trend contributed to the terminal life satisfaction decline over time, life satisfaction trends for the control groups should be upward sloping or flat. Figure 8 in Appendix 1 shows that there is at most a small decline in average life satisfaction over time for all three control groups.

Previous literature suggests that more satisfied people tend to live longer (see Veenhoven 2008 for a review). Here, reverse causality is problematic for two reasons. First, the age restriction for the time-to-death sample may lead to an increasingly negatively selected sample over time. Second, at the individual level, onset of disease, onset of terminal life satisfaction decline, and age at death are endogenous. To address the concern of increasing sample selectivity, I dropped the age restriction, i.e., I added 383 people who died before age 60 to the sample. Figure 9 in Appendix 1 shows that average life satisfaction trends exhibit the same slopes of decline, thereby ruling out this potential explanation. To address the concern of endogeneity at the individual level, I re-estimated average life satisfaction trends using objective death probabilities instead of actual distance to death. Objective death probabilities were retrieved from period life tables (German Federal Statistical Office 2012a, b) and indicate a person's probability of dying before her next birthday. If population aging rather than endogenous shifts in the onset of terminal life satisfaction decline led to the decline in terminal life satisfaction over time, average life satisfaction trends should be downward sloping. Figure 10 in Appendix 1 shows that for West Germans aged 60 and older, this was indeed the case.

Finally, to investigate whether differential attrition patterns over time contributed to the downward slope of average life satisfaction trends, I estimated a linear probability model for study dropout using the unbalanced time-to-death sample. Table 2 in Appendix 1 reports the regression results. It shows for the last five years of life that less satisfied elderly West Germans are more likely to drop out of the GSOEP, but that the attrition pattern with respect to life satisfaction did not change over time.

\footnotetext{
${ }^{16}$ This result also holds if I control for relative as opposed to absolute income (e.g., poverty indicators, distance to median income). Moreover, I find that an urban-rural drift in the place of living is unlikely to account for the decline in terminal life satisfaction over time. Since information on community size only became available in 1995, I did not control for it in the regressions presented here.

${ }^{17}$ A general aging-unrelated time trend may result from (unobserved) time-varying factors such as, for example, technological progress that is unrelated to aging, change in nutritional habits, or improvements in access to health care.
} 


\section{Life-expectancy approach}

This section investigates whether increases in satisfied lifetime compensated for the worse final period of life such that people became better off in terms of overall life satisfaction (i.e., the proportion of expected satisfied lifetime after age 60) with improved longevity. Again, details on the estimation are provided first.

\subsection{Empirical strategy}

Time trends of satisfied life expectancy at age 60 were estimated based on Sullivan's method (Sullivan 1971). ${ }^{18}$ The idea of this method is quite simple. It divides total life expectancy at age 60 into satisfied and dissatisfied life expectancy at age 60 by combining data from two different sources. While the person-years lived in each age interval are obtained from period life tables, satisfaction prevalence rates for the corresponding age intervals are estimated based on survey data and then used to weight the person-years lived in each age interval. After weighting, the computation of satisfied life expectancy is equivalent to that of standard life expectancy. That is, satisfied life expectancy at age 60 is computed by summing up the weighted personyears lived after age 60 and then dividing it by the number of 60 -year-old survivors. Formally, Sullivan's estimator is defined as

$$
\hat{e}_{60}^{s}=\frac{\sum_{x \in A_{60}} \hat{h}_{x, n_{x}}^{s} L_{x, n_{x}}}{l_{60}},
$$

where $A_{60}$ represents the set of starting ages $x$ such that $x \geq 60, \hat{h}_{x, n_{x}}^{s}$ denotes the sample fraction of satisfied survey respondents in the age interval $\left[x, x+n_{x}\right), L_{x, n_{x}}$ indicates the person-years lived in the age interval $\left[x, x+n_{x}\right)$, and $l_{60}$ gives the number of 60-year-old survivors. ${ }^{19}$ Dissatisfied life expectancy at age 60 is estimated either by replacing $\hat{h}_{x, n_{x}}^{s}$ with the sample fraction of dissatisfied survey respondents, $\hat{h}_{x, n_{x}}^{d s}=1-\hat{h}_{x, n_{x}}^{s}$, in (2) or by directly subtracting satisfied life expectancy at age 60 from total life expectancy at age 60 .

I used five-year age intervals, i.e., $n_{x}=n=5$ for all but the last age interval, which ranged from 85 to the oldest observed age. Gender-age-specific satisfaction prevalence rates were estimated by the gender-age-specific sample fractions of GSOEP respondents in any of the three states: dissatisfied (life satisfaction of 0 to 6), moderately satisfied (life satisfaction of 7 or 8), and very satisfied (life satisfaction of 9 or 10). The threshold values correspond to the first and third quartiles of the pooled

\footnotetext{
${ }^{18}$ This method differs from the multistate life table method in that it uses stock rather than flow data. Despite this difference, both methods produce similar results if changes over time are smooth and occur regularly (Mathers and Robine 1997).

${ }^{19}$ To understand (2), consider the following example. Suppose that in a population 100 people at age 60 are still alive. Half of them suddenly drop dead on their 61st birthday (i.e., they live another year), the other half on their 63rd birthday (i.e., they live another three years). During their remaining lifetime, half of the people are satisfied, while the other half is not. In this case, total life expectancy at age 60 equals two years $(=(100+50+50) / 100)$, whereof one year is spent in satisfaction, on average. That is, satisfied life expectancy at age 60 equals one $(=(100 \cdot 0.5+50 \cdot 0.5+50 \cdot 0.5) / 100)$.
} 
life satisfaction distribution in the life-expectancy sample. Consistent with the data from period life tables, I estimated the satisfaction prevalence rates using three-year averages. ${ }^{20}$ Estimates were weighted using cross-sectional survey weights in order to account for the sampling structure of the GSOEP.

To allow for comparisons of satisfied life expectancy at age 60 across time, estimates are reported for the years 1985, 1990, 2000, and 2010 in both absolute (number of years) and relative (proportion of life) terms. For testing purposes, standard errors were derived based on the delta method (see Appendix 2). They differ from those that are usually employed in the literature, because I use longitudinal data and pool the data of three years when estimating the satisfaction prevalence rates for a given year. While testing, I implicitly assume that the covariance between two life expectancy estimates can be ignored because I independently computed the standard errors of satisfied life expectancy across the different years. Since this assumption is most plausible for the largest time difference, I only report test results for the difference between 1985 and 2010. For this difference, less than 5\% of the observations stem from respondents who took part in the survey in both years (including the surrounding years).

\subsection{Results}

Table 1 presents the estimates of satisfied life expectancy at age 60 for West Germans without migration backgrounds by gender and year and contrasts them with the increase in total life expectancy at age 60. Between 1985 and 2010, total life expectancy for a 60-year-old man continuously grew from 17.1 years in 1985 to 21.4 years in 2010. In 2010, he was expected to spend about 15 years of his life in states of satisfaction, which made up for $70 \%$ of his remaining lifetime. More than half of the additional lifetime was, on average, spent in states of satisfaction, despite the steady decline in very satisfied lifetime after 1985 . For a 60 -year-old woman, the pattern across time was very similar, but the increase in average satisfied lifetime of 1.4 years was substantially lower than that for a 60 -year-old man. It only accounted for $40 \%$ of the overall increase in a 60-year-old woman's lifetime. Nevertheless, in 2010, women at the age of 60 were also expected to spend a fairly high fraction (about two-thirds) of their remaining lifetime in states of satisfaction.

However, there also was a flip side to the coin. The extension of the terminal decline period as well as the larger fraction of dissatisfied West German elderly peo-

\footnotetext{
${ }^{20}$ Sample sizes used to estimate the gender-age-specific satisfaction prevalence rates in a given year range from 120 to 1546 observations. Two exceptions represent the estimates for men aged 85 and older in 1985 and 1990.
} 


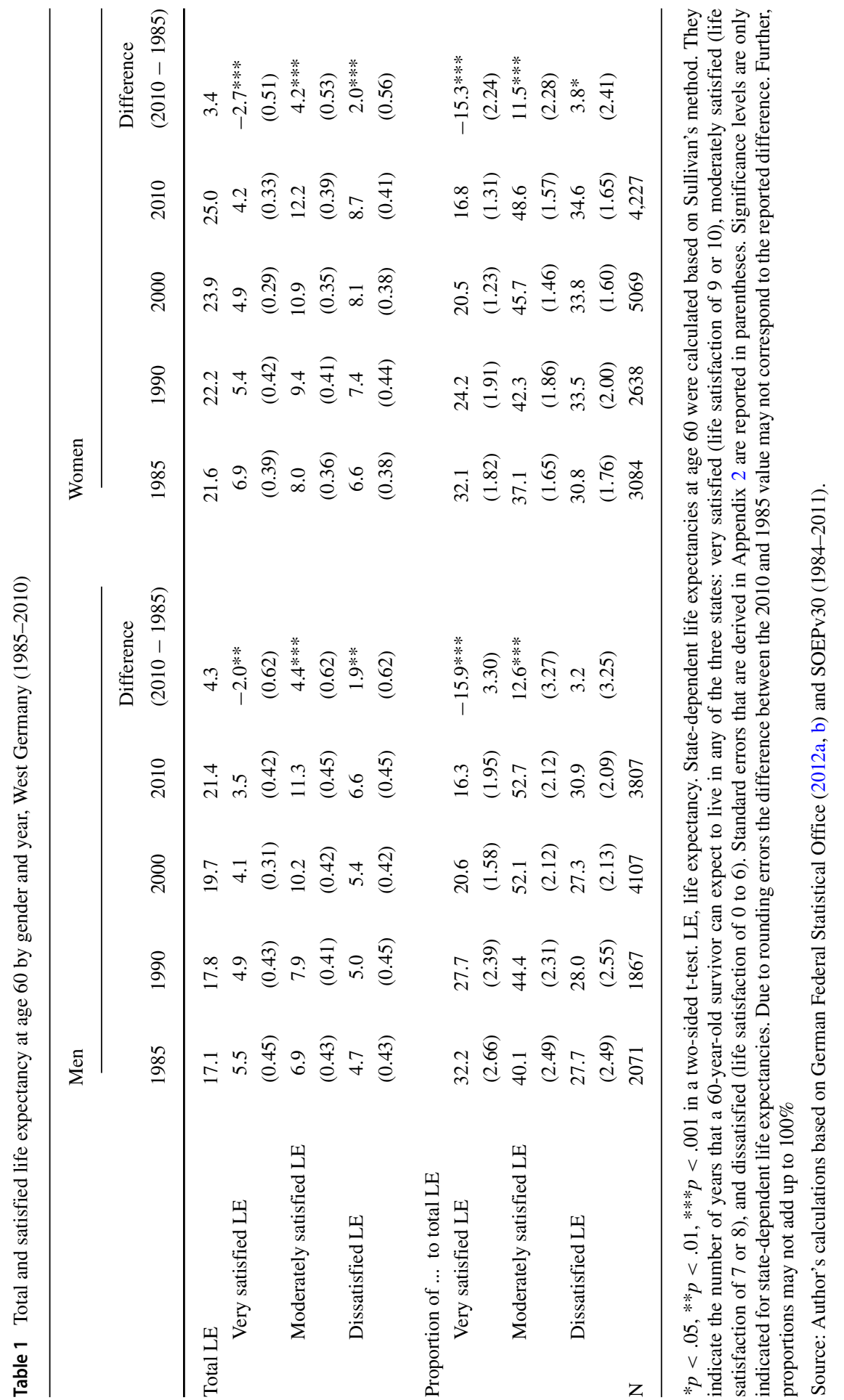


ple within five years of death (cf. results in Section 5.2) were reflected in a significant rise of expected dissatisfied lifetime. The rise in expected dissatisfied lifetime outweighed the rise in expected satisfied lifetime such that the proportion of satisfied lifetime to total lifetime fell after $1985 .^{21}$ In 2010 , the decline in the proportion of satisfied lifetime equaled 3 to 4 percentage points. This corresponds to a $5 \%$ reduction in the proportion of satisfied lifetime or a $12 \%$ increase in the proportion of dissatisfied lifetime, on average. The decline in the proportion of satisfied lifetime is statistically significant for both men and women, albeit for men only at the $10 \%$ level in a one-sided test. Thus, if we rely on the assumption that at the age of 60 , people prefer a high proportion of satisfied lifetime over a higher number of satisfied life years (cf. Section 3), the life-expectancy results suggest that the overall quality of life deteriorated with improved longevity in West Germany between 1985 and $2010 .^{22}$

To better understand what contributed to the changes in satisfied life expectancy at age 60 over time, I estimated counterfactual satisfied life expectancy at age 60, keeping age-specific mortality rates constant as of 1985. This allows me to distinguish between changes that result directly from declines in mortality and changes that result both indirectly from declines in mortality and from changes in satisfaction prevalence. ${ }^{23}$ Figure 4 presents the estimates of counterfactual life expectancy at age 60 by gender and year and contrasts them with the estimates of actual life expectancy at age 60 that were presented in Table 1. At each point in time, total life expectancy - as indicated by the full length of a bar — is divided into the number of years that a 60-year-old survivor can expect to live in the very satisfied, moderately satisfied, and dissatisfied states. Changes in satisfied life expectancy that result from changes in satisfaction prevalence and the indirect mortality effect are shown within the bar charts for counterfactual life expectancy. In contrast, changes that result solely from declines in mortality (direct mortality effect) are assessed by comparing changes of actual and counterfactual satisfied life expectancy across the bar charts for men or for women.

A comparison of counterfactual estimates within the bar charts for men and women suggests that the observed decrease in very satisfied life expectancy between 1985 and 2010 was fully attributable to a decline in satisfaction prevalence over time, as reflected by the strong decrease in counterfactual very satisfied life expectancy over time. ${ }^{24}$ The direct effect of declining mortality did not contribute to the decline in very satisfied life expectancy, as the comparison of actual and counterfactual estimates shows. The opposite holds true for the changes in dissatisfied life expectancy. Almost the full increase in dissatisfied life expectancy at age 60 between 1985 and

\footnotetext{
${ }^{21}$ This holds because the proportion of expected satisfied lifetime was over $50 \%$ in 1985 .

${ }^{22}$ Again, the life-expectancy results are slightly more pessimistic for women. This might be explained by a level effect. With increasing life expectancy, over time it might get harder to ensure a high quality of life towards the end of people's lives.

${ }^{23}$ If I were to vary only the mortality rates, I would clearly capture the effect of population aging. However, I would neglect the effect that declining mortality may have on satisfaction due to a shift in the onset of terminal decline, possibly overestimating the negative effect of population aging.

${ }^{24}$ Further analysis revealed that time-in-panel effects strongly contributed to the decline in satisfaction prevalence over time.
} 


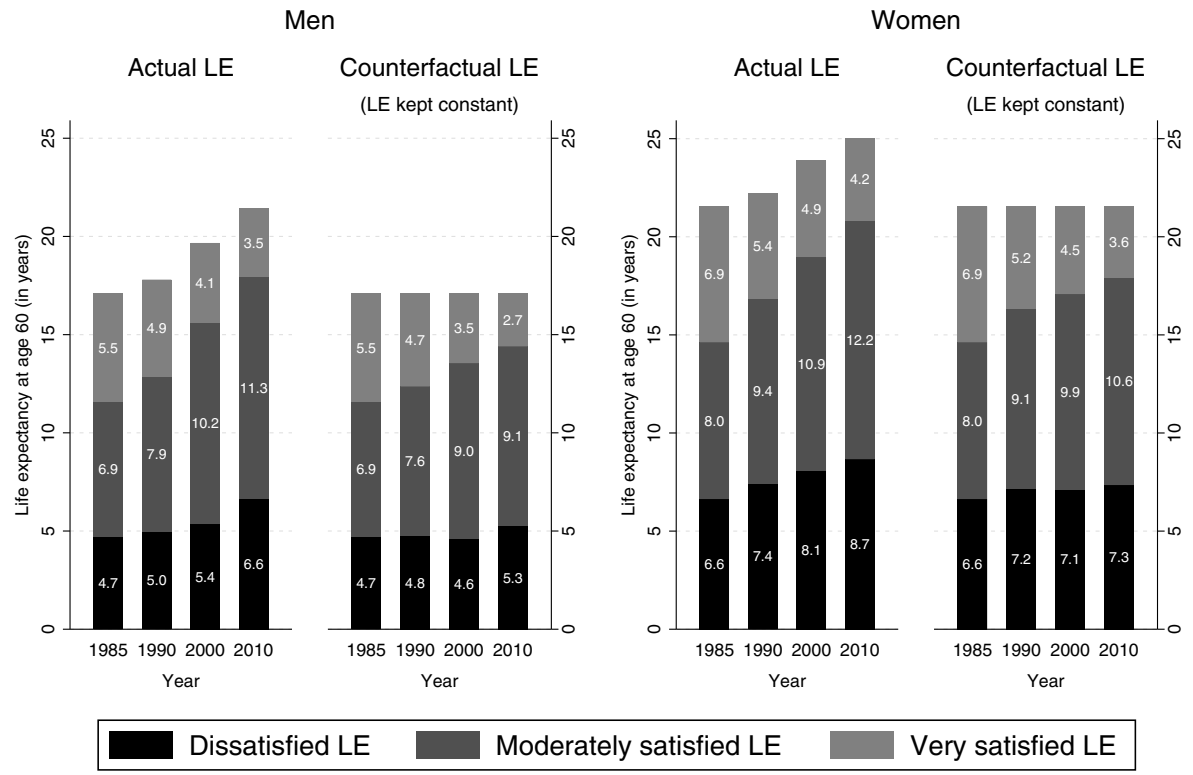

Fig. 4 Actual and counterfactual satisfied life expectancy at age 60 by gender and year, West Germany (1985-2010). LE, life expectancy. This figure shows the evolution of total and satisfied life expectancy at age 60 in West Germany by gender (actual LE, cf. Table 1) and contrasts it with the evolution that would result if mortality rates were kept constant as of 1985 (counterfactual LE). In each year, total life expectancy is divided into the expected number of very satisfied (life satisfaction of 9 or 10), moderately satisfied (life satisfaction of 7 or 8), and dissatisfied (life satisfaction of 0 to 6) life years. Changes in satisfied life expectancy that only result from reduced mortality (direct mortality effect) are assessed by comparing changes of satisfied life expectancy across actual and counterfactual bar charts for men and for women. Changes that result from changes in satisfaction prevalence but also include an indirect mortality effect (due to possible shifts in the onset of satisfaction decline) are assessed by comparing satisfied life expectancy within the counterfactual bar charts for men or for women across time. Source: Author's calculations based on German Federal Statistical Office (2012a, b) and SOEPv30 (1984-2011)

2010 is explained by direct declines in mortality. Changes in satisfaction prevalence over time contributed, if at all, only very little to the increase in dissatisfied life expectancy over time. This result is crucial because it suggests that explanations other than improved longevity, including period, cohort, and time-in-panel effects, are unlikely to explain the increase in dissatisfied life expectancy.

\subsection{Sensitivity tests}

The life satisfaction scale in the GSOEP does not indicate where on the scale "dissatisfied" stops and "satisfied" starts. This challenges the interpretation of scores. To explore the sensitivity of the life-expectancy results, I used two alternative classification schemes. First, I used the midpoint of the Likert scale to distinguish between dissatisfied and moderately satisfied states and kept the threshold value for the very satisfied state constant. Second, I used an equal point split classification. That is, 
I classified respondents as dissatisfied (moderately satisfied, very satisfied) if they reported a life satisfaction score between 0 and 4 (5 and 7, 8 and 10).

Figure 11 in Appendix 1 depicts the results. Under the midpoint split classification (left panel), I continue to find qualitatively the same results. That is, between 1985 and 2010, there was again a strong increase in dissatisfied life expectancy at age 60 in both absolute and relative terms. However, the change in relative terms was no longer statistically significant. Under the equal point split classification (right panel), a different picture emerges. Here, expected satisfied lifetime at age 60 increased between 1985 and 2010, as did expected dissatisfied lifetime, but the increase in the former was, on average, more than 10 times larger than in the latter. Therefore, with a threshold value of four for dissatisfied states, the proportion of expected satisfied lifetime to expected total lifetime at age 60 no longer decreased, but stayed at a constant level of about 91 to $92 \%$, which corresponded to a total of about 20 expected satisfied life years across sexes in 2010.

\subsection{Discussion}

The life-expectancy results differ from those reported in Perenboom et al. (2004) and Yang (2008). This discrepancy in findings may be explained by three crucial differences across studies. First, the other two studies rely on different measures of well-being. While Perenboom et al. (2004) measure hedonic well-being based on the negative items of the Bradburn Affect Balance Scale, ${ }^{25}$ Yang (2008) uses happiness - a concept that is more closely related to life satisfaction. However, in his study, happiness is only measured on a 3-point scale. This may hide important data patterns, in particular, if states of satisfaction and dissatisfaction are pooled in the intermediate category. In fact, I can replicate his findings when pooling states of satisfaction and dissatisfaction in the intermediate category under the equal point split classification. Second, the other two studies focus on earlier time periods. Since in earlier time periods life expectancy levels were lower, the differences in results may also be explained by a level effect. In all three studies, the observed gender differences would be consistent with such a level effect. Third, the other two studies focus on different countries. Veenhoven (1996a) showed that happy life expectancy strongly differs across countries, and that contextual factors such as affluence, freedom, and tolerance explain $70 \%$ of the statistical variance in happy life expectancy. In line with his findings, I find that the results for West Germany are worse than for the Netherlands and the United States.

\section{Mechanisms}

This section discusses two important mechanisms for the decline in terminal life satisfaction over time: health and social isolation.

\footnotetext{
${ }^{25}$ The Bradburn Affect Balance Scale gathers information on feelings. It consists of 10 items: five positive and five negative (Bradburn 1969).
} 


\subsection{Health}

Health gradually declines with age (DePinho 2000; Rosenthal and Kavic 2004) and poor health is negatively related to life satisfaction (e.g., Oswald and Powdthavee 2008). Thus, one obvious channel through which increased longevity can affect life satisfaction is health.

Figure 5 shows time trends of the main health indicators in the GSOEP by time to death. It suggests that a deterioration of health is likely an important mechanism. Three out of the four objective health indicators show a sharp rise with increased longevity (top and middle graphs). The share of elderly people within five years of death who had a severe disability more than doubled between 1985 and $2011 .{ }^{26}$ In 2011, more than every second elderly person exhibited a health impairment immediately before death. Subjective health measures (bottom graphs) also indicate a significant decline in health for all but the last year of life, however, the size of the decline is small. One likely explanation for this difference between objective and subjective health measures is interpersonal comparison (Steffel and Oppenheimer 2009). ${ }^{27}$

Figure 12 in Appendix 1 provides further evidence for the health mechanism. It demonstrates that the decline in terminal life satisfaction over time becomes much smaller after controlling for health indicators in individual-level life satisfaction regressions. Health satisfaction explains roughly one-third of the decline in life satisfaction of respondents who were two or three years before death, while the disability status fully explains the decline in life satisfaction of respondents who were four or five years before death. Overall, these results support the expansion of morbidity hypothesis (Gruenberg 1977; Olshansky et al. 1991).

\subsection{Social isolation}

Social isolation and inactivity are negatively associated with life satisfaction (e.g., Chappell and Badger 1989; Pinquart and Sörensen 2000; Powdthavee 2008), also prior to death (Gerstorf et al. 2016). Among various measures of social isolation, disconnectedness with social peers and a low number of friends have the most detrimental impact on life satisfaction (Chappell and Badger 1989; Pinquart and Sörensen 2000). Due to a reduction of multigenerational households (German Federal Statistical Office 2016) and increased geographical distance between adult children and elderly parents in Germany (e.g., Mahne and Huxhold 2017), fewer personal contacts with family members likely contributed to the decline in terminal life satisfaction over time. Moreover, given the increased variation in longevity at age 60 in industrialized countries (Engelman et al. 2010), it is possible that elderly West Germans became more likely to experience a friend's death early in life, reducing the frequency

\footnotetext{
${ }^{26}$ The decline in the share of severely disabled elderly people between 1996 and 2000 resulted from a revision of the assessment criteria for legally attested disability status in 1996.

${ }^{27}$ Interpersonal comparisons do not equally apply to life satisfaction as well (Junghaenel et al. 2018). One possible explanation for this observation is that interpersonal comparisons are more difficult to make when rating life satisfaction because life satisfaction is affected by many domains of life.
} 

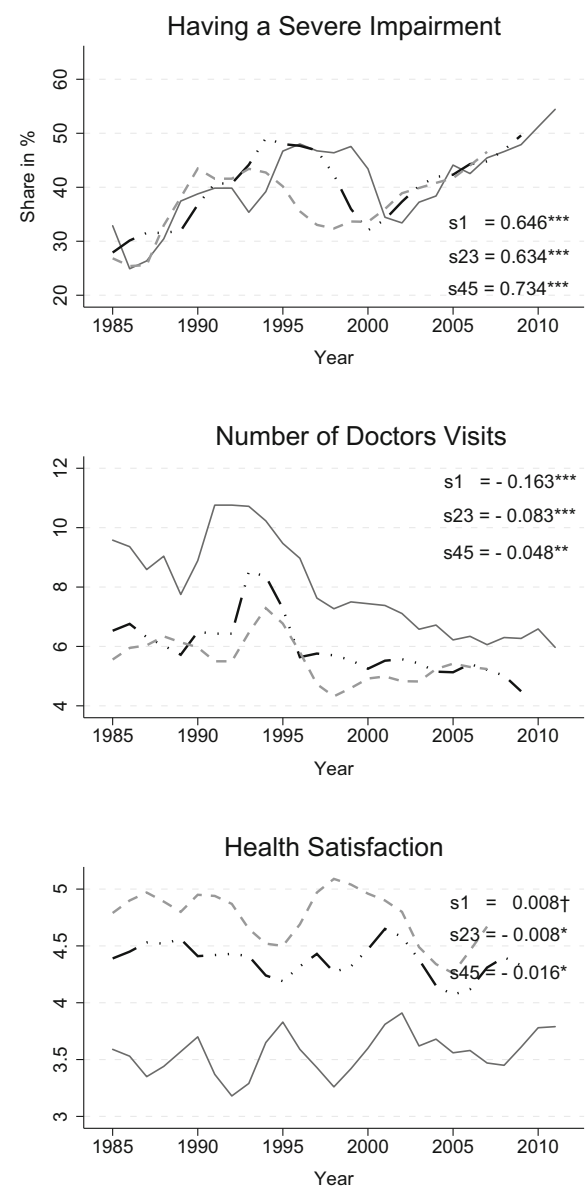
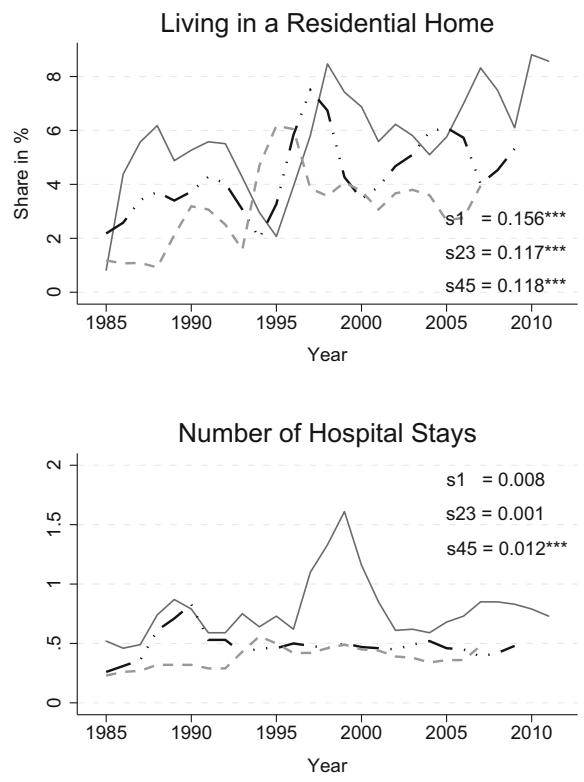

Self-Assessed Health Status

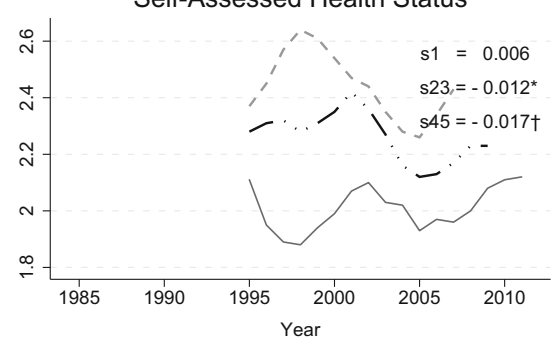

Time to death: $\quad 1$ Year $\quad \ldots, 2$ or 3 Years _ - - - 4 or 5 Years

Fig. 5 Average health indicators for elderly West Germans within five years of death, 1985-2011, by time to death. Estimates in a given year represent three-year averages. Having a severe health impairment is measured by legally attested disability status. Doctor visits refer to the last three months. Hospital stays refer to the last year. Health satisfaction is measured on an 11-point Likert scale, ranging from 0 (very dissatisfied) to 10 (very satisfied). Self-assessed health status is measured on a 5-point scale, ranging from 1 (bad) to 5 (very good). Due to missing information (information not collected in 1990 and 1993) and item non-response estimates were obtained from a smaller sample than in Fig. 3 for all but the health satisfaction indicator. s1, s23, and s45 indicate the slope estimates for fitted linear trend lines (not shown in graphs). ${ }^{\dagger} p<.10 ; * p<.05 ; * * p<.01 ; * * *<<.001$. Source: Author's calculations based on GBE (2016) and SOEPv30 (1984-2013)

of personal contacts with friends over time. In addition, fewer personal contacts with family and friends might have resulted from reduced mobility because mobility strongly declines with age among the elderly people (Ferrucci et al. 2016), likely due to impoverished health. 

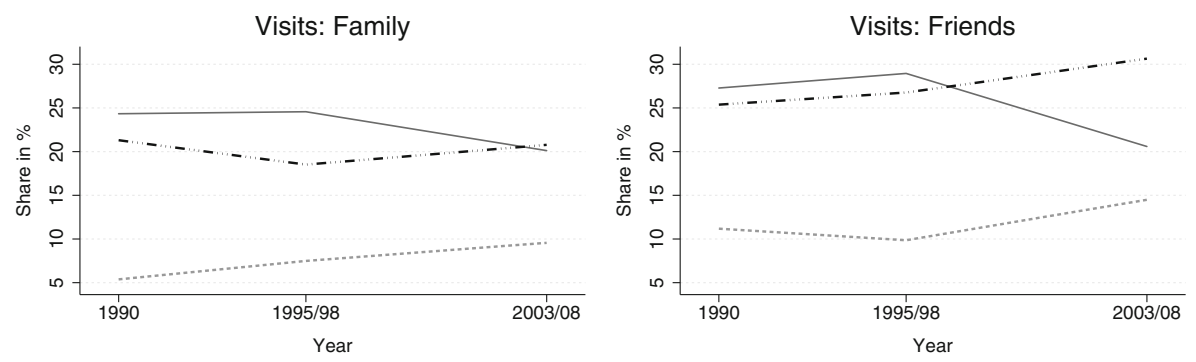

Frequency of visits: _ Monthly _ _....... Less than monthly $\quad \ldots \ldots \ldots$ Never

Fig. 6 Share of elderly West Germans within five years of death that had mutual visits with family and friends, 1990-2008, by frequency of visits. Due to missing information (information only available for five years) and item non-response estimates were obtained from a smaller sample than in Fig. 3. A distinction by time to death (cf. Figs. 3 and 5) was not meaningful because of small sample sizes. Shares do not add to $100 \%$ as the category "weekly visits" is not shown. Source: Author's calculations based on GBE (2016) and SOEPv30 (1984-2013)

Figure 6 shows that the frequency of mutual visits with family and friends strongly decreased over time for the West German elderly who were within their last five years of life. ${ }^{28}$ Between 1990 and 2008, the shares of the elderly with less than monthly mutual visits (only for mutual visits with friends) and without any visits (for both types of mutual visits) each increased by more than five percentage points. I investigated three additional indicators of social isolation: single household status, partnership status, and widowhood. I find that these indicators contributed to the decline in terminal life satisfaction over time as well, also after controlling for health. ${ }^{29}$ Overall, these results suggest that increased social isolation was an additional explanation for the steady decline in terminal life satisfaction over time.

\section{Conclusion}

Given the rapid increase in human life expectancy throughout the last decades, this study asks: Are longer lives more satisfied lives? Using data from the German SocioEconomic Panel, this study suggests that the answer might be no. Although expected satisfied lifetime increased for West Germans at the age of 60 by two years between 1985 and 2010, this increase likely did not compensate for the substantial losses of life satisfaction that occurred at the end of people's lives. In 2010, average life satisfaction scores in the last five years of life were roughly one-third to half a standard deviation lower than in 1985. Moreover, the period of terminal satisfaction decline was substantially longer. With, on average, slightly more than two additional dissat-

\footnotetext{
${ }^{28}$ Information on these indicators was only collected in five years between 1985 and 2011. Therefore, in this figure, I pool the data of two years together (if applicable) and do not distinguish by time to death.

${ }^{29}$ The magnitude of effect was similar to the one observed for the other two social isolation indicators, but it did not work as much through the health channel (results available upon request).
} 
isfied life years, 60-year-old survivors in 2010 were expected to spend $10 \%$ more of their remaining lifetime in states of dissatisfaction, which suggests a drop in this study's measure of overall quality of life. Nevertheless, in 2010, the proportion of expected satisfied lifetime to expected total lifetime at age 60 was still relatively high, with an average level of about $65 \%$ to $70 \%$.

To better understand what contributed to the decline in terminal life satisfaction in West Germany, I explored the role of two potential mechanisms: health and social isolation. Several health indicators (e.g., severe disability, number of hospitalizations) indicated a deterioration of the end-of-life health status over time and, thus, provided support for the expansion of morbidity hypothesis (Gruenberg 1977; Olshansky et al. 1991). Among all health indicators, the increase in legally attested disability had the most detrimental impact on terminal life satisfaction. All measures of social isolation contributed to the decline in terminal satisfaction over time, but individual-level life satisfaction regressions indicated that increased isolation mainly worked through the health channel. These results are in line with studies that show that the onset of disability relates to a lasting well-being decline (Lucas 2007; Oswald and Powdthavee 2008), and that a socially active life is associated with higher late-life well-being, less pronounced late-life decline, and a later onset of terminal satisfaction decline (Gerstorf et al. 2016).

One likely explanation for the findings of this study is the decline in sudden death. Over the last three decades, age-standardized mortality from ischaemic heart disease has fallen by more than half in high income countries (Finegold et al. 2013; Hartley et al. 2016). So while in earlier times, when smoking was still very common, quite healthy and satisfied people suddenly dropped dead, nowadays new medical technologies (e.g., drug-eluting stents) allow the medical profession to extend people's lives even with disease. As a consequence, people are much more likely to experience novel types of diseases as well as an increased burden and complexity of multimorbidity (WHO 2010). Moreover, thinking of slowly progressing diseases such as Alzheimer's disease or dementia that come with a progressive decline in memory and cognitive function and eventually lead to severe disability (Alzheimer's Association 2016), it is very plausible that people are much less satisfied throughout their final period of life nowadays. Overall, higher dissatisfaction levels may result from the burden associated with disease, including increased social isolation, as well as the fact that people know that there is no cure or modifying treatment for a disease (Daviglus et al. 2010).

The final conclusion that the overall quality of life decreased with improved longevity between 1985 and 2011 rests on a very strong assumption, namely that at the age of 60 , people value a high proportion of satisfied to total lifetime more strongly than the actual number of satisfied life years. Although consistent with the literature (Pennington et al. 2015; Ahlert et al. 2016; Fischer et al. 2018), this assumption may not hold. Another related issue is that of acceptable satisfaction levels. Many people would argue that satisfaction levels above the neutral (i.e., 5 on the 0 to 10 scale) are still quite satisfying and, thus, the elderly in our sample, though more dissatisfied in the final period of life, were still quite satisfied in 2011. However, there is a well-documented issue of over-reporting satisfaction scores in surveys with faceto-face interviews (see Diener et al. 2013 for review). Even satisfaction scores of 
about four (on the 0 to 10 scale) may be predictive of suicide (Koivumaa-Honkanen et al. 2001). If people nevertheless believe that life is still satisfying at very low satisfaction scores (i.e., three and lower), then the final conclusion of this study will no longer hold.

Should people and policymakers further invest in life extensions? This study shows that it is important to complement investments that extend the length of human life with investments that improve the quality of life in old age. Under-investments in the latter result in declining satisfaction levels at the end of people's lives. Qualityof-life-improving policies may have a more positive effect on increasing overall life satisfaction. This is because they would increase satisfaction during a person's lifetime, and furthermore, may also extend the length of life itself since more satisfied people tend to live longer (Veenhoven 2008; Steptoe et al. 2015).

Which quality-of-life-improving policies should be targeted? As suggested by the analysis of potential mechanisms, potential candidates would be policies that aim to prevent noncommunicable diseases (e.g., via reduced tobacco use, healthy diets, or physical activity) and policies that aim to achieve a better integration of the elderly in today's societies (e.g., via better provision of public transportation in remote areas). Further research on these and other potential mechanisms is required to decide upon the policies that are most promising. Moreover, future research needs to explore potential heterogeneity in order to better target policies to groups of recipients.

\section{Appendix 1: Supplementary tables and figures}
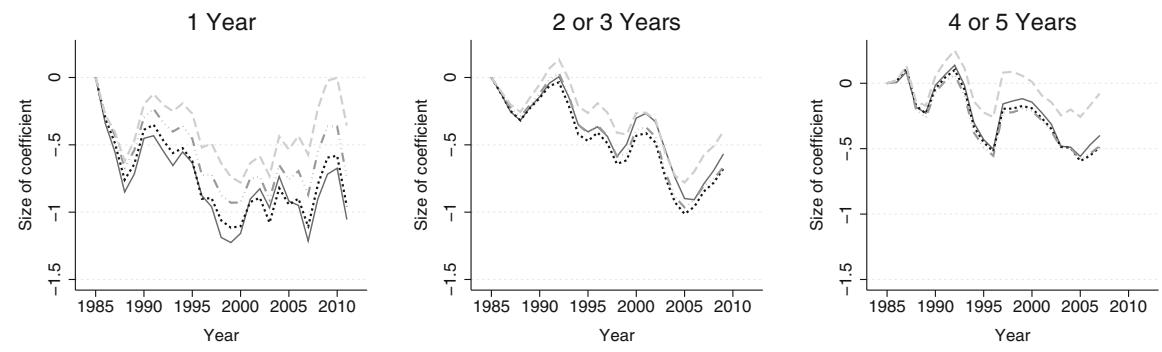

Specification: — Baseline

Add controls

Add cohort effects

Add time-in-panel effects

Fig. 7 Role of compositional, cohort, and time-in-panel effects: Year dummy coefficient estimates from terminal life satisfaction regressions, by time to death and regression specification. This figure shows the change of year dummy coefficient estimates after sequentially adding controls for compositional effects (add controls), cohort effects (add cohort effects), and time-in-panel effects (add time-in-panel effects) to weighted individual-level life satisfaction regressions that linearly regress terminal life satisfaction on a set of year dummies (baseline specification). Separate regressions were estimated by time to death and results are shown in distinct graphs (with increasing time to death from the left to the right). Coefficient estimates are relative to the year 1985. Trends for the baseline specification correspond to those in Fig. 3. Upward tilting trends indicate a contribution of the added set of controls to the decline of terminal life satisfaction over time. Source: Author's calculations based on GBE (2016) and SOEPv30 (1984-2013) 


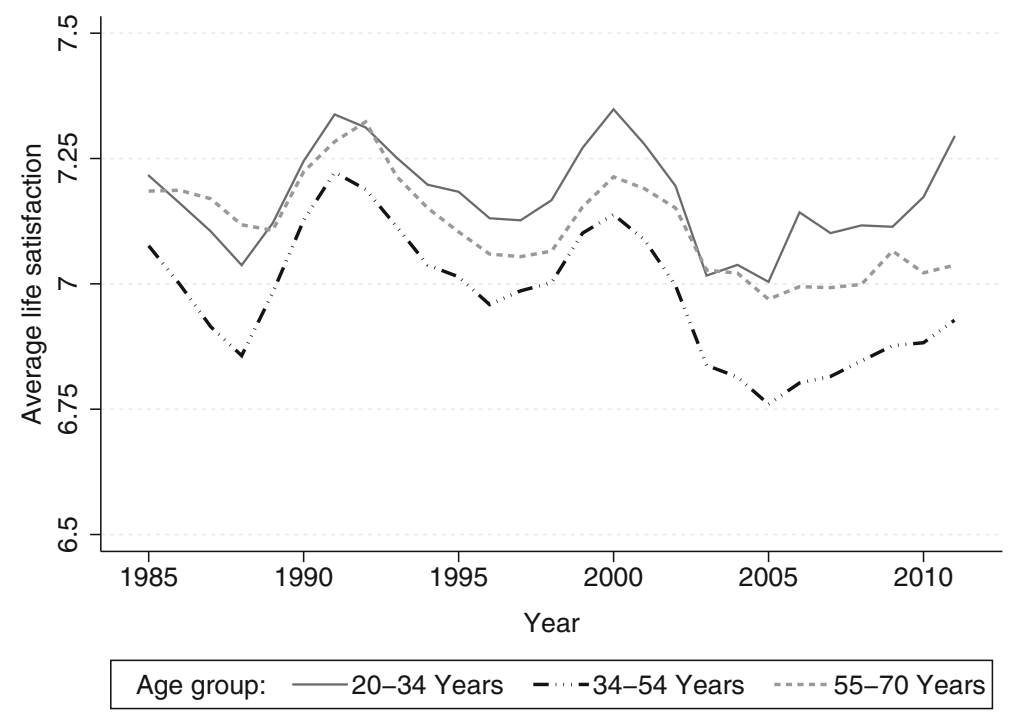

Fig. 8 Average life satisfaction for West German adults, 1985-2011, by (age based) control group. Estimates in a given year represent three-year averages. Estimates were adjusted for time-in-panel effects. Like in Fig. 3, estimates refer to West Germans without a migration background. Non-declining time trends suggest that macroeconomic effects or a general time trend did not contribute to the decline of terminal life satisfaction over time. Source: Author's calculations based on GBE (2016) and SOEPv30 (1984-2013)
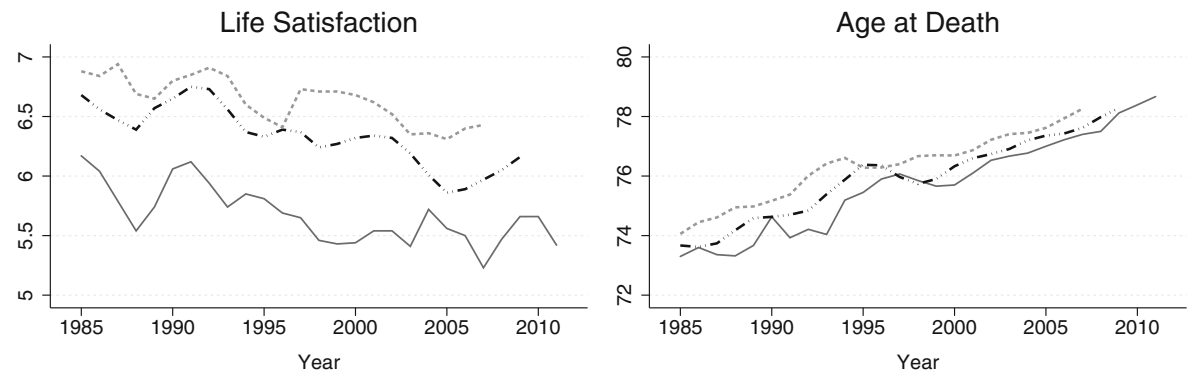

Time to death: — 1 Year $\quad-\ldots \ldots 2$ or 3 Years ......... 4 or 5 Years

Fig. 9 Average life satisfaction and average age at death for West German adults within five years of death, 1985-2011, by time to death. Estimates in a given year represent three-year averages. The sample corresponds to that in Fig. 3, except that it also includes respondents who died at the ages 18 to 54 . Time trends that are similar to those in Fig. 3 suggest that the age restriction does not come with an increasingly negatively selected sample over time, and hence, does not explain the decline of terminal life satisfaction over time. Source: Author's calculations based on GBE (2016) and SOEPv30 (1984-2013) 

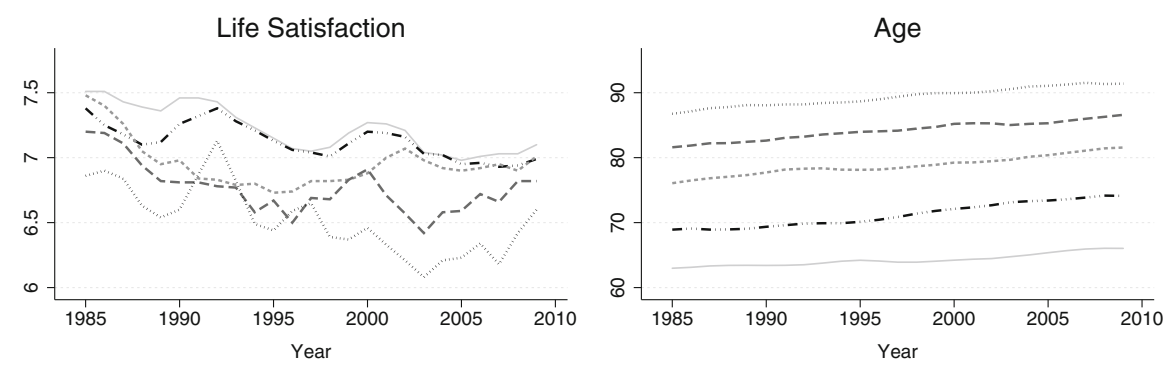

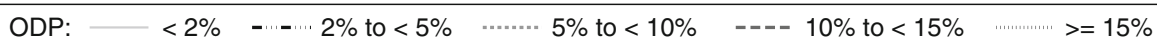

Fig. 10 Average life satisfaction and average age for elderly West Germans, 1985-2011, by objective death probability (ODP). ODPs indicate a person's period life table probability of dying before her next birthday. Estimates in a given year represent three-year averages. The sample corresponds to that in Fig. 3, except that it also includes non-deceased respondents. Downward sloping time trends suggest that the decline of terminal satisfaction over time was not driven by endogenous shifts in the onset of disease, the onset of terminal satisfaction decline, and age at death. Source: Author's calculations based on German Federal Statistical Office (2012a,b) and SOEPv30 (1984-2013)

Table 2 Linear probability model estimates for study dropout

\begin{tabular}{ll}
\hline & Dropout \\
\hline Constant & 0.029 \\
& $(0.030)$ \\
Life satisfaction & $-0.004^{\dagger}$ \\
& $(0.002)$ \\
Post1995 & -0.000 \\
& $(0.020)$ \\
Post1995 $\times$ life satisfaction & 0.003 \\
& $(0.003)$ \\
2 or 3 years before death & $0.036^{* * *}$ \\
& $(0.006)$ \\
Male & -0.009 \\
& $(0.006)$ \\
Age & $0.001^{\dagger}$ \\
& $(0.000)$ \\
Low education & -0.006 \\
Poor household & $(0.006)$ \\
Single household & $0.017^{*}$ \\
Adj. R2 & $(0.008)$ \\
$\mathrm{N}$ & $-0.023^{* * *}$ \\
\hline
\end{tabular}

${ }^{\dagger} p<.10 ; * p<.05 ; * * p<.01 ;$

$* * * p<.001$. The sample

corresponds to that in Fig. 3 ,

except that it excludes

respondents who were one year

before death. Low education is

an indicator for those with less

than 11 years of schooling. Poor household is an indicator for those living in households with net household income below the $60 \%$ poverty line. Clustered standard errors are reported in parentheses. Source: Author's calculations based on SOEPv30 (1984-2013)
$0.036^{* * *}$$$
-0.009
$$

$0.001^{\dagger}$

$0.017 *$

(0.006)

7383 
Midpoint Split Classification

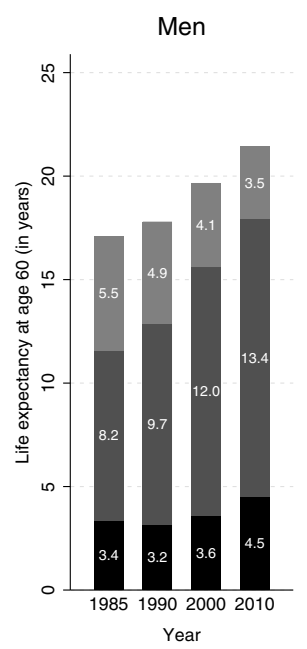

Women

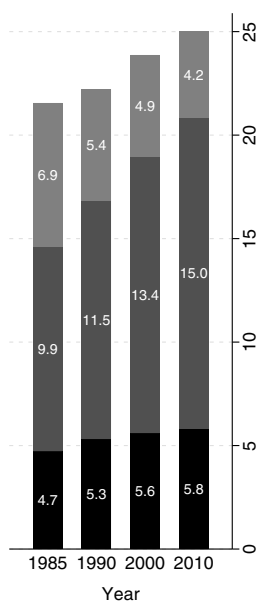

Equal Point Split Classification

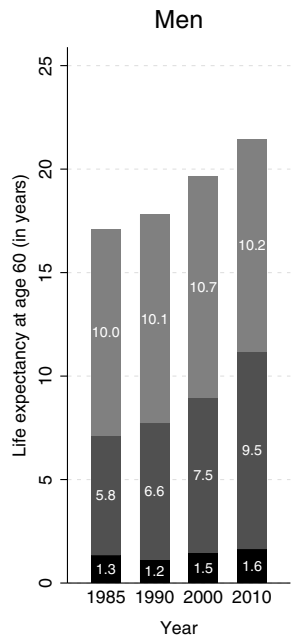

Women

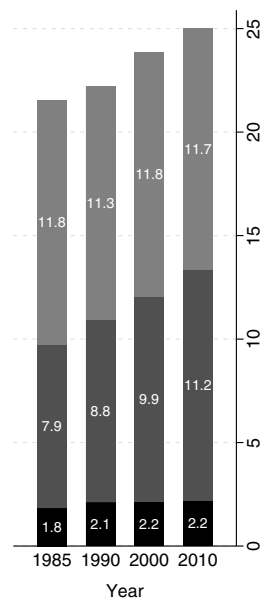

Dissatisfied LE

Moderately satisfied LE

Very satisfied LE

Fig. 11 Total and satisfied life expectancy at age 60 by gender, year, and classification scheme, West Germany (1985-2010). LE, life expectancy. This figure shows the sensitivity of the life-expectancy results (cf. Tab 1 and Fig. 4) to alternative classification schemes. Under the midpoint split classification (equal point split classification), respondents are classified as dissatisfied if their life satisfaction lies between 0 and 5 ( 0 and 4), as moderately satisfied if their life satisfaction lies between 6 and 8 (5 and 7), and as very satisfied if their life satisfaction lies between 9 and 10 (8 and 10). Source: Author's calculations based on German Federal Statistical Office (2012a, b) and SOEPv30 (1984-2011)
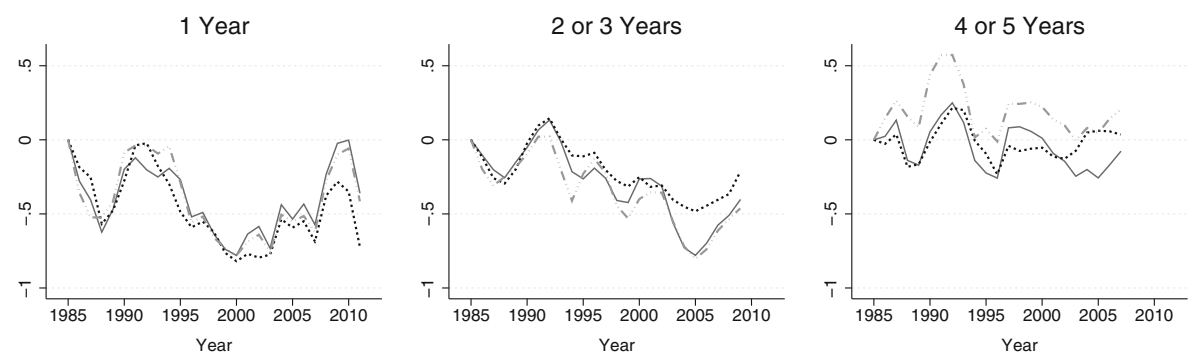

Specification:

Adj. baseline

.......... Add health satisfaction

-....... Add disability status

Fig. 12 Role of health: Year dummy coefficient estimates from terminal life satisfaction regressions, by time to death and regression specification. This figure shows the change of year dummy coefficient estimates after adding a linear term for health satisfaction (add health satisfaction) or indicators for the disability status (add disability status) to the weighted individual-level life satisfaction regressions of the final specification in Fig. 7 (now called adjusted baseline). Indicators for the disability status were constructed based on the disability degree: not disabled (0), low (1 to 49), medium (50 to 79), high (80 to 99), and fully disabled (100). Again, separate regressions were estimated by time to death and results are shown in distinct graphs (with increasing time to death from the left to the right). Coefficient estimates are again relative to the year 1985. Upward tilting trends indicate a contribution of the added health indicator to the decline of terminal life satisfaction over time. Source: Author's calculations based on GBE (2016) and SOEPv30 (1984-2013) 


\section{Appendix 2: Standard error of satisfied life expectancy at age 60}

In this appendix, I derive the standard error of satisfied life expectancy at age 60, which is used to test for significant differences across time. Using Chiang's (1984) result, I first rewrite the formula of satisfied life expectancy in terms of survival probabilities, $p_{x, n_{x}}$. Then, I use the delta method to obtain the standard errors for this non-linear function of random variables.

Chiang (1984) showed that the person-years lived in the age interval $\left[x, x+n_{x}\right)$, $L_{x, n_{x}}$, are a linear function of the cumulative survival probability up to age $x$, which itself is a product of the probabilities of surviving from each starting age $x$ to age $x+n_{x}, p_{x, n_{x}}$ :

$$
\begin{aligned}
L_{x, n_{x}} & =n_{x} l_{x+n_{x}}+n_{x} a_{x}\left(l_{x}-l_{x+n_{x}}\right) \\
l_{x} & =l_{0} \prod_{i \in B_{x}} p_{i, n_{i}},
\end{aligned}
$$

where $B_{x}=\{i \in B: x>i\}$ and $a_{x}$ the average proportion lived by people who die in the age interval $\left[x, x+n_{x}\right.$ ). Inserting (3) and (4) in the formula of satisfied life expectancy at age 60 (see (2) for its empirical counterpart), I obtain

$$
e_{60}^{s}=\frac{\sum_{x \in A_{60}} h_{x, n_{x}}^{s}\left[n_{x} \prod_{i \in B_{x+n_{x}}} p_{i, n_{i}}+n_{x} a_{x}\left(l_{0} \prod_{i \in B_{x}} p_{i, n_{i}}-l_{0} \prod_{i \in B_{x+n_{x}}} p_{i, n_{i}}\right)\right]}{l_{0} \prod_{i \in B_{60}} p_{i, n_{i}}} .
$$

That is, satisfied life expectancy at age 60 is a nonlinear function of the age-specific survival probabilities, $p_{x, n_{x}}$, and the satisfaction prevalence rates, $h_{x, n_{x}}^{s}$, all of which are random variables.

Next, the delta method is applied to this non-linear function of random variables. As the age-specific satisfaction prevalence rates are estimated based on a different data source than the age-specific survival probabilities, they can be considered independent of the age-specific survival probabilities, and the covariance terms between these variables can be ignored (Mathers 1991). Moreover, given that the survival probabilities for two non-overlapping age intervals are estimated based on two distinct groups of people, the estimated survival probabilities are uncorrelated across age intervals (Chiang 1960). This argument also holds for German period life tables, which rely on repeated cross-sectional data and pool the data of three years to obtain the life table estimates for a given year.

A similar argument would apply to the age-specific sample fractions of satisfied survey respondents, if pooled data of repeated cross-sections were used. In my case, however, this argument does not apply because I use longitudinal data and compute three-year averages. Taking into account that I use five-year age intervals, the sample fractions of satisfied GSOEP respondents at a given point in time are correlated across two adjacent age intervals, while they continue to be uncorrelated across the other non-overlapping age intervals. Thus, the delta method yields the following variance of satisfied life expectancy at age 60 :

$$
\begin{aligned}
\operatorname{Var}\left(e_{60}^{s}\right)= & \sum_{x \in A_{60}}\left(\frac{\partial e_{60}^{s}}{\partial p_{x, n_{x}}}\right)^{2} \operatorname{Var}\left(p_{x, n_{x}}\right)+\sum_{x \in A_{60}}\left(\frac{\partial e_{60}^{s}}{\partial h_{x, n_{x}}^{s}}\right)^{2} \operatorname{Var}\left(h_{x, n_{x}}^{s}\right) \\
& +2 \sum_{x \in A_{60} \backslash w} \frac{\partial e_{60}^{s}}{\partial h_{x, n_{x}}^{s}} \frac{\partial e_{60}^{s}}{\partial h_{x+n_{x}, n_{x+n_{x}}}^{s}} \operatorname{Cov}\left(h_{x, n_{x}}^{s}, h_{x+n_{x}, n_{x+n_{x}}}^{s}\right),
\end{aligned}
$$


where $w$ is the starting age for the oldest age interval. The first term describes the variation in survival (or mortality), while the second and third terms describe the variation in satisfaction prevalence.

According to Newman (1988), the variation resulting from mortality rates will be negligible if the sample size of the survey population relative to the sample size of the population on which the mortality data are based is small. Therefore, I ignore the first term in (6). ${ }^{30}$ After explicitly writing down the derivatives, the standard error of satisfied life expectancy at age 60 is then given by

$$
\begin{aligned}
\operatorname{se}\left(e_{60}^{s}\right)= & \left(\frac{\sum_{x \in A_{60}}\left(\frac{L_{x, n_{x}}}{l_{60}}\right)^{2} \operatorname{Var}\left(h_{x, n_{x}}^{s}\right)}{n}\right. \\
& \left.+\frac{2 \sum_{x \in A_{60} \backslash w} \frac{L_{x, n_{x}}}{l_{60}} \frac{L_{x+n_{x}, n_{x+n_{x}}}}{l_{60}} \operatorname{Cov}\left(h_{x, n_{x}}^{s}, h_{x+n_{x}, n_{x+n_{x}}}^{s}\right)}{n}\right)^{\frac{1}{2}},
\end{aligned}
$$

where $\mathrm{n}$ is the sample size of the survey population which is used to estimate the satisfaction prevalence rates, $h_{x, n_{x}}^{s}$. The estimator is obtained by using the information from period life tables and replacing the population variances and covariances in the final equation with their sample counterparts. Unlike in studies that use repeated cross-sectional data, I compute clustered variances and covariances for the satisfaction prevalence rates in a given year to account for serial correlation across observations of the same respondent within age intervals and across two adjacent age intervals.

Acknowledgements I thank the editor, Alessandro Cigno, the associate editor, Andrew Clark, and two anonymous referees for many helpful comments and suggestions. The paper benefited from discussions with Pieter Bakx, Pietro Biroli, Paul Frijters, Kristina Hess, Wanda Mimra, Andrew Oswald, Rainer Winkelmann, and Christian Waibel. I also acknowledge helpful comments from audiences at various conferences, seminars, and workshops.

Funding Open Access funding provided by Universität Zürich.

\section{Declarations}

Conflict of interest The author declares no competing interests.

Open Access This article is licensed under a Creative Commons Attribution 4.0 International License, which permits use, sharing, adaptation, distribution and reproduction in any medium or format, as long as you give appropriate credit to the original author(s) and the source, provide a link to the Creative Commons licence, and indicate if changes were made. The images or other third party material in this article are included in the article's Creative Commons licence, unless indicated otherwise in a credit line to the material. If material is not included in the article's Creative Commons licence and your intended use is not permitted by statutory regulation or exceeds the permitted use, you will need to obtain permission directly from the copyright holder. To view a copy of this licence, visit http://creativecommons.org/licenses/by/4.0/.

\footnotetext{
${ }^{30}$ In practice, this is a suitable approach, which under the stated conditions produces almost the same standard errors as if the first term was not ignored (Jagger et al. 2014).
} 


\section{References}

Ahlert M, Breyer F, Schwettmann L (2016) How you ask is what you get: framing effects in willingnessto-pay for a QALY. Soc Sci Med 150(Supplement C):40-48

Alzheimer's Association (2016) 2016 Alzheimer's disease facts and figures. Alzheimers Dement 12(4):459-509

Baetschmann G (2014) Heterogeneity in the relationship between happiness and age: evidence from the German Socio-Economic Panel. Ger Econ Rev 15(3):393-410

Baird BM, Lucas RE, Donnellan MB (2010) Life satisfaction across the lifespan: findings from two nationally representative panel studies. Soc Indic Res 99(2):183-203

Benjamin DJ, Heffetz O, Kimball MS, Rees-Jones A (2012) What do you think would make you happier? What do you think you would choose? Am Econ Rev 102(5):2083-2110

Benjamin DJ, Heffetz O, Kimball MS, Szembrot N (2014) Beyond happiness and satisfaction: toward well-being indices based on stated preference. Am Econ Rev 104(9):2698-2735

Berg AI, Hassing L, Thorvaldsson V, Johansson B (2011) Personality and personal control make a difference for life satisfaction in the oldest-old: findings in a longitudinal population-based study of individuals 80 and older. Eur J Ageing 8(1):13-20

Blanchflower DG (2021) Is happiness U-shaped everywhere? Age and subjective well-being in 145 countries. J Popul Econ 34(2):575-62

Blanchflower DG, Oswald AJ (2004) Well-being over time in Britain and the USA. J Public Econ 88(7):1359-1386

Blanchflower DG, Oswald AJ (2008) Is well-being U-shaped over the life cycle? Soc Sci Med 66(8):17331749

Blanchflower DG, Oswald AJ (2019) Do humans suffer a psychological low in midlife? Two approaches (with and without controls) in seven data sets. In: Rojas M (ed) The economics of happiness: how the Easterlin paradox transformed our understanding of well-being and progress. Springer International Publishing, Cham, pp 439-453

Bradburn NM (1969) The structure of psychological well-being. Aldine Publishing Company, Chicago

Case A, Deaton A (2015) Rising morbidity and mortality in midlife among white non-Hispanic Americans in the 21st century. Proc Natl Acad Sci 112(49):15078-15083

Chappell NL, Badger M (1989) Social isolation and well-being. J Gerontol 44(5):S169-S176

Chatterji S, Byles J, Cutler D, Seeman T, Verdes E (2015) Health, functioning, and disability in older adults - present status and future implications. Lancet 385(9967):563-575

Chetty R, Stepner M, Abraham S, Lin S, Scuderi B, Turner N, Bergeron A, Cutler D (2016) The association between income and life expectancy in the United States, 2001-2014. JAMA 315(16):1750-1766

Chiang CL (1960) A stochastic study of the life table and its applications: I. probability distributions of the biometric functions. Biometrics 16(4):618-635

Chiang CL (1984) The life table and its applications. Krieger Publishing Company, Malabar

Clark AE, Oswald AJ (1994) Unhappiness and unemployment. Econ J 104(424):648-659

Clark AE, Diener E, Georgellis Y, Lucas RE (2008) Lags and leads in life satisfaction: a test of the baseline hypothesis. Econ J 118(529):F222-F243

Crimmins EM, Beltrán-Sánchez H (2011) Mortality and morbidity trends: is there compression of morbidity? J Gerontol: Ser B 66(1):75-86

Daviglus ML, Bell CC, Berrettini W, Bowen PE, Sander ConnollyJE, Cox NJ, Dunbar-Jacob JM, Granieri EC, Hunt G, McGarry K, Patel D, Potosky AL, Sanders-Bush E, Silberberg D, Trevisan M (2010) National institutes of health state-of-the-science conference statement: preventing Alzheimer disease and cognitive decline. Ann Intern Med 153(3):176-181

Deaton A (2008) Income, health, and well-being around the world: evidence from the Gallup World Poll. J Econ Perspect 22(2):53-72

DePinho RA (2000) The age of cancer. Nature 408(6809):248-254

Di Tella R, MacCulloch RJ, Oswald AJ (2001) Preferences over inflation and unemployment: evidence from surveys of happiness. Am Econ Rev 91(1):335-341

Diener E, Emmons RA, Larsen RJ, Griffin S (1985) The satisfaction with life scale. J Pers Assess 49:71-75

Diener E, Suh EM, Lucas RE, Smith HL (1999) Subjective well-being: three decades of progress. Psychol Bull 125(2):276-302

Diener E, Ronald I, Tay L (2013) Theory and validity of life satisfaction scales. Soc Indic Res 112(3):497527 
Ditto PH, Druley JA, Moore KA, Danks JH, Smucker WD (1996) Fates worse than death: the role of valued life activities in health-state evaluations. Health Psychol 15(5):332-343

Dolan P, Peasgood T, White M (2008) Do we really know what makes us happy? A review of the economic literature on the factors associated with subjective well-being. J Econ Psychol 29:94-122

Easterlin RA (2002) Happiness in economics. Edward Elgar, Cheltenham

Easterlin RA (2003) Explaining happiness. Proc Natl Acad Sci 100(19):11176-11183

Engelman M, Canudas-Romo V, Agree EM (2010) The implications of increased survivorship for mortality variation in aging populations. Popul Dev Rev 36(3):511-539

Ferrucci L, Cooper R, Shardell M, Simonsick EM, Schrack JA, Kuh D (2016) Age-related change in mobility: perspectives from life course epidemiology and geroscience. J Gerontol: Ser A 71(9):11841194

Finegold JA, Asaria P, Francis DP (2013) Mortality from ischaemic heart disease by country, region, and age: statistics from World Health Organisation and United Nations. Int J Cardiol 168(2):934-945

Fischer B, Telser H, Zweifel P (2018) End-of-life healthcare expenditure: testing economic explanations using a discrete choice experiment. J Health Econ 60:30-38

Fleurbaey M, Schwandt H (2015) Do people seek to maximize their subjective well-being? IZA Discussion Papers 9450, Institute for the Study of Labor (IZA)

Frijters P, Haisken-DeNew JP, Shields MA (2004a) Investigating the patterns and determinants of life satisfaction in Germany following reunification. J Hum Resour 39(3):649-674

Frijters P, Haisken-DeNew JP, Shields MA (2004b) Money does matter! Evidence from increasing real income and life satisfaction in East Germany following reunification. Am Econ Rev 94(3):730-740

Frijters P, Clark AE, Krekel C, Layard R (2020) A happy choice: wellbeing as the goal of government. Behav Public Policy 4(2):126-165

German Federal Statistical Office (2012a) Periodensterbetafeln für Deutschland. Allgemeine Sterbetafeln, abgekürzte Sterbetafeln und Sterbetafeln, 1871/1881 bis 2008/2010. Wiesbaden. www.destatis.de/DE/Publikationen/Thematisch/Bevoelkerung/Bevoelkerungsbewegung/Periodenster betafelnPDF_5126202.pdf?_blob=publicationFile. Accessed 29 February 2016

German Federal Statistical Office (2012b) Periodensterbetafeln für Deutschland. Früheres Bundesgebiet, neue Länder sowie die Bundesländer, 2009/2011. Wiesbaden. www.destatis.de/DE/Publikationen/ Thematisch/Bevoelkerung/Bevoelkerungsbewegung/PeriodensterbetafelnBundeslaender5126204117 004.pdf?_blob=publicationFile. Accessed 29 February 2016

German Federal Statistical Office (2016) Zusammenleben von Generationen. Wiesbaden. https:// www.destatis.de/DE/PresseService/Presse/Pressekonferenzen/2016/zusammenleben_generationen/ zusammenleben_generationen_uebersicht.html. Accessed 15 January 2018

Gerstorf D, Ram N, Estabrook R, Schupp J, Wagner GG, Lindenberger U (2008a) Life satisfaction shows terminal decline in old age: longitudinal evidence from the German Socio-Economic Panel Study (SOEP). Dev Psychol 44(4):1148-1159

Gerstorf D, Ram N, Röcke C (2008b) Decline in life satisfaction in old age: longitudinal evidence for links to distance-to-death. Psychol Aging 23(1):154-168

Gerstorf D, Ram N, Mayraz G, Hidajat M, Lindenberger U, Wagner GG, Schupp J (2010) Late-life decline in well-being across adulthood in Germany, the UK, and the US: something is seriously wrong at the end of life. Psychol Aging 25(2):477-485

Gerstorf D, Hoppmann CA, Löckenhoff CE, Infurna FJ, Schupp J, Wagner GG, Ram N (2016) Terminal decline in well-being: the role of social orientation. Psychol Aging 31(2):149-165

Gesundheitsberichterstattung des Bundes (GBE) (2016) Sterbeziffern je 100000 Einwohner (altersstandardisiert) (ab 1980). Gliederungsmerkmale: Jahre, Region, Alter, Geschlecht, Nationalit?t, Todesursachen laut Europ?ischer Kurzliste, Art der Standardisierung. www.gbe-bund.de/stichworte/ Todesursachenstatistik.html. Accessed 14 June 2016

Graham C, Ruiz Pozuelo J (2017) Happiness, stress, and age: how the U curve varies across people and places. J Popul Econ 30(1):225-264

Gruenberg EM (1977) The failures of success. Milbank Mem Fund Q Health Soc 55(1):3-24

Gwozdz W, Sousa-Poza A (2010) Ageing, health and life satisfaction of the oldest old: an analysis for Germany. Soc Indic Res 97(3):397-417

Hartley A, Marshall DC, Salciccioli JD, Sikkel MB, Maruthappu M, Shalhoub J (2016) Trends in mortality from ischemic heart disease and cerebrovascular disease in Europe. Circulation 133(20):1916-1926

Helliwell JF (2003) How's life? Combining individual and national variables to explain subjective wellbeing. Econ Model 20(2):331-360 
Helliwell JF (2006) Well-being, social capital and public policy: what's new? Econ J 116(510):C34-C45

Jagger C, Robine JM (2011) Healthy life expectancy. In: Rogers GR, Crimmins ME (eds) International handbook of adult mortality. Springer, Dordrecht, pp 551-568

Jagger C, Van Oyen H, Robine JM (2014) Health expectancy calculation by the Sullivan method: a practical guide (4th ed.). Technical Report, Institute for Ageing, Newcastle University

Junghaenel DU, Broderick JE, Schneider S, May M, Bolton A, McCarrier KP, Stassek LM, Keithly SC, Stone AA (2018) Frames of reference in self-reports of health, well-being, fatigue, and pain: a qualitative examination. Appl Res Qual Life 13(3):585-601

Kassenboehmer SC, Haisken-DeNew JP (2009) You're fired! The causal negative effect of entry unemployment on life satisfaction. Econ J 119(536):448-462

Kassenboehmer SC, Haisken-DeNew JP (2012) Heresy or enlightenment? The well-being age U-shape effect is flat. Econ Lett 117(1):235-238

Koivumaa-Honkanen H, Honkanen R, Viinamäki H, Heikkilä K, Kaprio J, Koskenvuo M (2001) Life satisfaction and suicide: a 20-year follow-up study. Am J Psychiatry 158(3):433-439

Kunzmann U, Little TD, Smith J (2000) Is age-related stability of subjective well-being a paradox? Crosssectional and longitudinal evidence from the Berlin Aging Study. Psychol Aging 15(3):511-526

Lucas RE (2007) Long-term disability is associated with lasting changes in subjective well-being: evidence from two nationally representative longitudinal studies. J Pers Soc Psychol 92(4):717-730

Mahne K, Huxhold O (2017) Nähe auf Distanz: Bleiben die Beziehungen zwischen älteren Eltern und ihren erwachsenen Kindern trotz wachsender Wohnentfernungen gut?. In: Mahne K, Wolff JK, Simonson J, Tesch-Römer C (eds) Altern im Wandel: Zwei Jahrzehnte Deutscher Alterssurvey (DEAS). Springer VS, Wiesbaden, pp 215-230

Marmot M, Allen J, Boyce T, Goldblatt P, Morrison J (2020) Health equity in England: the Marmot review 10 years on. Institute of Health Equity, London

Mathers CD (1991) Health expectancies in Australia 1981 and 1988. Australian Institute of Health: AGPS, Canberry

Mathers CD, Robine JM (1997) How good is Sullivan's method for monitoring changes in population health expectancies. J Epidemiol Community Health 51(1):80-86

McNamee P, Mendolia S (2014) The effect of chronic pain on life satisfaction: evidence from Australian data. Soc Sci Med 121(Supplement C):65-73

Newman SC (1988) A Markov process interpretation of Sullivan's index of morbidity and mortality. Stat Med 7(7):787-794

OECD (2016) Life expectancy at birth (indicator). https://doi.org/10.1787/27e0fc9d-en. Accessed 15 July 2016

Olshansky SJ, Rudberg MA, Carnes BA, Cassel CK, Brody JA (1991) Trading off longer life for worsening health: the expansion of morbidity hypothesis. J Aging Health 3(2):194-216

Oreopoulos P (2007) Do dropouts drop out too soon? Wealth, health and happiness from compulsory schooling. J Public Econ 91(11-12):2213-2229

Oswald AJ, Powdthavee N (2008) Does happiness adapt? A longitudinal study of disability with implications for economists and judges. J Public Econ 92(5):1061-1077

Palgi Y, Shrira A, Ben-Ezra M, Spalter T, Shmotkin D, Kavé G (2010) Delineating terminal change in subjective well-being and subjective health: brief report. J Gerontol: Ser B 65(1):61-64

Pennington M, Baker R, Brouwer W, Mason H, Hansen DG, Robinson A, Donaldson C (2015) Comparing WTP values of different types of QALY gain elicited from the general public. Health Econ 24(3):280293

Perenboom RJM, Van Herten LM, Boshuizen HC, Van Den Bos GAM (2004) Trends in life expectancy in wellbeing. Soc Indic Res 65(2):227-244

Pinquart M, Sörensen S (2000) Influences of socioeconomic status, social network, and competence on subjective well-being in later life: a meta-analysis. Psychol Aging 15(2):187-224

Powdthavee N (2008) Putting a price tag on friends, relatives, and neighbours: using surveys of life satisfaction to value social relationships. J Socio-Econ 37(4):1459-1480

Realo A, Dobewall H (2011) Does life satisfaction change with age? A comparison of Estonia, Finland, Latvia, and Sweden. J Res Pers 45(3):297-308

Rosenthal RA, Kavic SM (2004) Assessment and management of the geriatric patient. Crit Care Med 32(4):S92-S105

Rubin EB, Buehler AE, Halpern SD (2016) States worse than death among hospitalized patients with serious illnesses. JAMA Intern Med 176(10):1557-1559

Schilling OK (2005) Cohort- and age-related decline in elder's life satisfaction: is there really a paradox? Eur J Ageing 2(4):254-263 
Schilling OK (2006) Development of life satisfaction in old age: another view on the 'paradox'. Soc Indic Res 75(2):241-271

Steffel M, Oppenheimer DM (2009) Happy by what standard? The role of interpersonal and intrapersonal comparisons in ratings of happiness. Soc Indic Res 92(1):69-79

Steptoe A, Deaton A, Stone AA (2015) Subjective wellbeing, health, and ageing. Lancet 385(9968):640648

Sullivan DF (1971) A single index of mortality and morbidity. HSMHA Health Rep 86(4):347-354

Veenhoven R (1996a) Happy life-expectancy. A comprehensive measure of quality-of-life in nations. Soc Indic Res 39(1): 1-58

Veenhoven R (1996b) The study of life satisfaction. In: Saris WE, Veenhoven R, Scherpenzeel AC, Bunting B (eds) A comparative study of satisfaction with life in Europe. Eötvös University Press, Budapest, pp 11-48

Veenhoven R (2008) Healthy happiness: effects of happiness on physical health and the consequences for preventive health care. J Happiness Stud 9(3):449-469

Veenhoven R (2015) Møller V, Rojas M The overall satisfaction with life: subjective approaches (1). In: Glatzer W, Camfield L (eds) Global handbook of quality of life: exploration of well-being of nations and continents. Springer, Netherlands, Dordrecht, pp 207-238

Vogel N, Gerstorf D, Ram N, Goebel J, Wagner GG (2017) Terminal decline in well-being differs between residents in East Germany and West Germany. Int J Behav Dev 41(1):115-126

Wagner GG, Frick JR, Schupp J (2007) The German Socio-Economic Panel Study (SOEP) - scope, evolution and enhancements. Schmollers Jahrb 127(1):139-169

Winkelmann L, Winkelmann R (1995) Happiness and unemployment: a panel data analysis for Germany. Konjunkturpolitik 41(4):293-307

World Health Organization (WHO) (2010) Global status report on noncommunicable diseases 2010. Geneva. https://www.who.int/nmh/publications/ncd_report2010/en/. Accessed 23 July 2019

Wunder C, Wiencierz A, Schwarze J, Küchenhoff H (2013) Well-being over the life span: semiparametric evidence from British and German longitudinal data. Rev Econ Stat 95(1):154-167

Yang Y (2008) Long and happy living: trends and patterns of happy life expectancy in the U.S., 1970-2000. Soc Sci Res 37(4):1235-1252

Publisher's note Springer Nature remains neutral with regard to jurisdictional claims in published maps and institutional affiliations. 